\title{
Amorphous Calcium Orthophosphates: Nature, Chemistry and Biomedical Applications
}

\author{
Sergey V. Dorozhkin
}

Kudrinskaja sq. 1-155, Moscow 123242, Russia

\begin{abstract}
Amorphous calcium orthophosphates (ACPs) represent a unique class of biomedically relevant calcium orthophosphate salts, having variable chemical but rather identical glass-like physical properties, in which there are neither translational nor orientational long-range orders of the atomic positions. Normally, ACPs are the first solid phases, precipitated after a rapid mixing of aqueous solutions containing ions of $\mathrm{Ca}^{2+}$ and $\mathrm{PO}_{4}{ }^{3-}$; however, other production techniques are known. Interestingly, but ACPs prepared by wet-chemical techniques were found to possess a relative constancy in their chemical composition over a relatively wide range of preparation conditions, which suggested the presence of a well-defined local structural unit, presumably, with the structure of $\mathrm{Ca}_{9}\left(\mathrm{PO}_{4}\right)_{6}$ - so-called a Posner's cluster. However, the presence of similar clusters in ACPs produced by other techniques remains uncertain. All ACPs are thermodynamically unstable compounds and, unless stored in dry conditions or doped by stabilizers, spontaneously they tend to transform to crystalline calcium orthophosphates, mainly to calcium apatites. This solution instability of ACPs and their easy transformation to crystalline phases are of a great biological relevance. Namely, the initiating role ACPs play in matrix vesicle biomineralization raises the importance of ACPs from a mere laboratory curiosity to that of a reasonable key intermediate in skeletal calcification. In addition, due to great chemical and structural similarities to the calcified tissues of mammals, as well as excellent biocompatibility and bioresorbability, all types of ACPs are very promising candidates to manufacture artificial bone grafts. In this review, current knowledge on occurrence, preparation, composition, structure, major properties and biomedical applications of ACPs have been summarized. To assist the readers in looking for the specific details on ACPs, a great number of references have been collected and systematized.
\end{abstract}

Keywords Amorphous, Calcium Orthophosphate, Apatite, Bone, Calcification, Posner's Cluster, Biomaterials, Bioceramics, Biomineralization

\section{Introduction}

In nature, amorphous phases exist extensively with readily moldable isotropic properties and of structure materials. For example, amorphous structures represent $\sim 20 \%$ of approximately 60 different inorganic compounds and minerals formed by living organisms. These biologically formed minerals are often called biominerals, while the process of their formation is called biomineralization[1]. A recent review on the subject indicates that many biominerals are formed from amorphous precursors and, furthermore, the amorphous phases may possess fluidic properties that impart new processing capabilities to the system[2]. Among the existing biogenic amorphous minerals, those composing from calcium orthophosphates are most abundant in teeth and exoskeletal structures of marine invertebrates[2-6]. On the other hand, the existence of similar amorphous calcium

* Corresponding author:

sedorozhkin@yandex.ru (Sergey V. Dorozhkin)

Published online at http://journal.sapub.org/ijmc

Copyright (C) 2012 Scientific \& Academic Publishing. All Rights Reserved phosphate (ACP, or ACPs if plural) minerals in vertebrate organisms has not been well established experimentally except in highly specialized locations such as the inner ear structures of embryonic sharks[1], mammalian milk[7,8], dental enamel[9], as well as in mitochondria[1] and sarcoplasmic reticulum[10] of some cells. Despite the intensive efforts, accumulated evidences for ACPs as an integral mineral component in major hard tissues, such as bones and teeth, are equivocal and for many years have been the subject of considerable debates[11-24]. However, recent studies on bone and teeth formation have suggested a presence of transient amorphous mineral precursors and a universal strategy for calcium carbonate-based and calcium orthophosphatebased biomineralization in both vertebrates and invertebrates[21-29].

An interesting study on a potential role of ACPs in facilitating assembly of nano-sized particles of HA into highly ordered structures has been published recently[30]. Higher order HA architectures were detected only when the starting particles were aggregates of nanodimensional spheres with HA cores and ACP shells. Surface ACPs initially linked HA nano-sized particles in a way that allowed a parallel orienta- 
tion of the nano-sized particles of HA and then was incorporated into HA by phase transformation to produce more ordered architectures with the characteristic features of apatites in biologic structures. Further, it was demonstrated that enamel- and bone-like apatites could be prepared by using nanodimensional HA and ACP under the controls of different biological additives[30]. This study points to an important role of ACP might play in bone formation. However, due to a lack of undeniable proofs, the question on the occurrence of ACP phases in newly mineralized tissues of vertebrates still remains unanswered[31].

The complete list of the available calcium orthophosphates combined with their standard abbreviations, chemical formulae and major properties is given in Table 1[32,33]. Since all of them belong to calcium orthophosphates, strictly speaking, all abbreviations in Table 1 are incorrect; however, they are extensively used in literature and there is no need to modify them. As the majority of calcium orthophosphates are crystalline, this review is devoted to the detailed description of ACPs (emphasized by bold font in Table 1), which is of a great biomedical importance due to its chemical and structural similarities to the calcified tissues of mammals. Furthermore, with a few important exceptions, neither ion-substituted forms of ACP[34-47,347], nor ACP- containing biocomposites[48-75] are considered and discussed. The readers interested in either these topics and/or other types of amorphous calcium phosphates (e.g., amorphous calcium polyphosphate[76-80] and amorphous calcium metaphosphate[81]) are referred to the original publications.

\section{Basic Definitions and Knowledge on the Amorphous State of Solids}

According to the thermodynamic laws, the perfect infinite crystals cannot exist in the real world. Various disorders in the forms of vacancies, interstitial atoms, impurities, dislocations, grain boundaries, surfaces and other interfaces disrupt the periodicity of otherwise "perfect" crystals and in many cases determine their physical properties. By contrast, highly disordered solids are those solids that are so irregular that the concept of a reference crystal lattice must be abandoned. Such highly disordered materials are called amorphous materials[82]. As Wikipedia, the free encyclopedia, has it: an amorphous (from the Greek term $\alpha \mu \rho \rho \varphi \varsigma_{\text {, }}$ which means "shapeless" or "without form") solid is a solid, in which there is no translational and orientational long-range order (LRO) of the atomic positions[83]. Early researchers categorized solids as amorphous or crystalline materials based on the macroscopic properties such as their external shapes, fracture mechanisms and optical properties long before X-ray diffraction techniques and other methods became available to reveal their atomic structures. Only in the past century, an understanding of the microscopic nature of amorphous materials has become possible[82]. However, there is still much debate concerning the exact nature of these materials. For example, in a recent article, Sheng, et al.,[84] have mentioned: "the atomic arrangements in amorphous alloys remain mysterious at present”.

Table 1. Existing calcium orthophosphates and their major properties[32,33]

\begin{tabular}{|c|c|c|c|c|c|}
\hline $\begin{array}{c}\mathrm{Ca} / \mathrm{P} \\
\text { molar } \\
\text { ratio } \\
\end{array}$ & Compound & Formula & $\begin{array}{c}\text { Solubility } \\
\text { at } 25^{\circ} \mathrm{C} \text {, } \\
-\log \left(\mathrm{K}_{\mathrm{s}}\right)\end{array}$ & $\begin{array}{c}\text { Solubility at } \\
25^{\circ} \mathrm{C}, \mathrm{g} / \mathrm{L}\end{array}$ & $\begin{array}{c}\mathrm{pH} \text { stability } \\
\text { range in aqueous } \\
\text { solutions at } 25^{\circ} \mathrm{C}\end{array}$ \\
\hline 0.5 & $\begin{array}{l}\text { Monocalcium phosphate monohydrate } \\
\text { (MCPM) }\end{array}$ & $\mathrm{Ca}\left(\mathrm{H}_{2} \mathrm{PO}_{4}\right)_{2} \cdot \mathrm{H}_{2} \mathrm{O}$ & 1.14 & $\sim 18$ & $0.0-2.0$ \\
\hline 0.5 & $\begin{array}{l}\text { Monocalcium phosphate anhydrous } \\
\text { (MCPA or MCP) }\end{array}$ & $\mathrm{Ca}\left(\mathrm{H}_{2} \mathrm{PO}_{4}\right)_{2}$ & 1.14 & $\sim 17$ & [c] \\
\hline 1.0 & $\begin{array}{l}\text { Dicalcium phosphate dihydrate } \\
\text { (DCPD), mineral brushite }\end{array}$ & $\mathrm{CaHPO}_{4} \cdot 2 \mathrm{H}_{2} \mathrm{O}$ & 6.59 & $\sim 0.088$ & $2.0-6.0$ \\
\hline 1.0 & $\begin{array}{l}\text { Dicalcium phosphate anhydrous (DCPA } \\
\text { or DCP), mineral monetite }\end{array}$ & $\mathrm{CaHPO}_{4}$ & 6.90 & $\sim 0.048$ & [c] \\
\hline 1.33 & Octacalcium phosphate (OCP) & $\mathrm{Ca}_{8}\left(\mathrm{HPO}_{4}\right)_{2}\left(\mathrm{PO}_{4}\right)_{4} \cdot 5 \mathrm{H}_{2} \mathrm{O}$ & 96.6 & $\sim 0.0081$ & $5.5-7.0$ \\
\hline 1.5 & $\alpha$-Tricalcium phosphate $(\alpha$-TCP) & $\alpha-\mathrm{Ca}_{3}\left(\mathrm{PO}_{4}\right)_{2}$ & 25.5 & $\sim 0.0025$ & [a] \\
\hline 1.5 & $\beta$-Tricalcium phosphate ( $\beta$-TCP) & $\beta-\mathrm{Ca}_{3}\left(\mathrm{PO}_{4}\right)_{2}$ & 28.9 & $\sim 0.0005$ & [a] \\
\hline $1.2-2.2$ & Amorphous calcium phosphates (ACP) & $\mathrm{Ca}_{x} \mathrm{H}_{y}\left(\mathrm{PO}_{4}\right)_{z} \cdot n \mathrm{H}_{2} \mathrm{O}, n=3-4.5 ; 15-20 \% \mathrm{H}_{2} \mathrm{O}$ & [b] & [b] & $\sim 5-12^{[\mathrm{d}]}$ \\
\hline $1.5-1.67$ & $\begin{array}{c}\text { Calcium-deficient hydroxyapatite } \\
\text { (CDHA or Ca-def HA })^{\text {[e] }}\end{array}$ & $\mathrm{Ca}_{10-x}\left(\mathrm{HPO}_{4}\right)_{x}\left(\mathrm{PO}_{4}\right)_{6-x}(\mathrm{OH})_{2-x}(0<x<1)$ & $\sim 85$ & $\sim 0.0094$ & $6.5-9.5$ \\
\hline 1.67 & Hydroxyapatite (HA, HAp or OHAp) & $\mathrm{Ca}_{10}\left(\mathrm{PO}_{4}\right)_{6}(\mathrm{OH})_{2}$ & 116.8 & $\sim 0.0003$ & $9.5-12$ \\
\hline 1.67 & Fluorapatite (FA or FAp) & $\mathrm{Ca}_{10}\left(\mathrm{PO}_{4}\right)_{6} \mathrm{~F}_{2}$ & 120.0 & $\sim 0.0002$ & $7-12$ \\
\hline 1.67 & Oxyapatite (OA, OAp or OXA) $)^{[f]}$ & $\mathrm{Ca}_{10}\left(\mathrm{PO}_{4}\right)_{6} \mathrm{O}$ & $\sim 69$ & $\sim 0.087$ & [a] \\
\hline 2.0 & $\begin{array}{l}\text { Tetracalcium phosphate (TTCP or } \\
\text { TetCP), mineral hilgenstockite }\end{array}$ & $\mathrm{Ca}_{4}\left(\mathrm{PO}_{4}\right)_{2} \mathrm{O}$ & $38-44$ & $\sim 0.0007$ & [a] \\
\hline
\end{tabular}

[a] These compounds cannot be precipitated from aqueous solutions

${ }^{[b]}$ Cannot be measured precisely. However, the following values were found: $25.7 \pm 0.1(\mathrm{pH}=7.40), 29.9 \pm 0.1(\mathrm{pH}=6.00), 32.7 \pm 0.1(\mathrm{pH}=5.28)$. The comparative extent of dissolution in acidic buffer is: ACP $>>\alpha-\mathrm{TCP}>>\beta$-TCP $>$ CDHA $>>$ HA $>$ FA

[c] Stable at temperatures above $100^{\circ} \mathrm{C}$

[d] Always metastable

e] Occasionally, it is called "precipitated HA (PHA)"

[f] Existence of OA remains questionable 
An amorphous structure is distinctly different from a densely packed assembly of microcrystals and is closely related to the structure of a liquid phase. Ideally, an amorphous solid should be described by the model of a perfectly random structure[85]; however, this is the boundary condition. As such, the structure of amorphous solids is normally described in terms of statistical distributions. Nevertheless, prior a further description, one must specify the existing atomic length scales. The shortest length scale usually used to describe the structure of a material consists of an atom and its nearest neighbors, out to perhaps two or three atoms distant. All solids and liquids have some structure on this scale, which is called a short-range order (SRO). For crystalline solids, structural order persists over much longer distances (at least, tens or hundreds of atomic distances), such that the atoms occupy sites in a periodic three-dimensional array. Such materials are said to have a LRO and include most metals and many covalently bonded solids. Non-crystalline solids, including glasses, lack a LRO and are said to be amorphous even though they can have a SRO that is quite well defined[86].

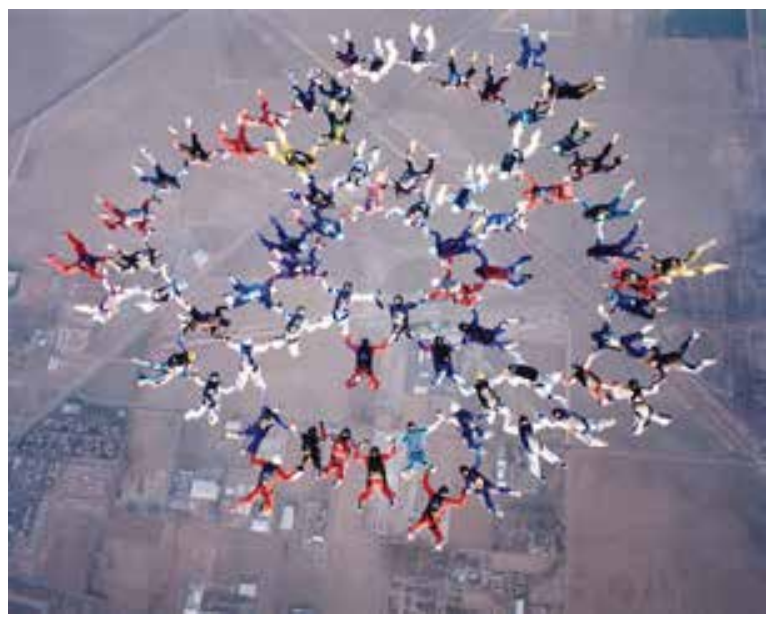

Figure 1. A formation of skydivers illustrates disorders on an intermediate length scale. Each skydiver has a simple set of rules for bonding to the next skydiver (SRO) but there is a sufficient flexibility for different patterns of ordering to be created on the scale of a few body lengths (MRO)

According to the available literature, for each particular atom of any solid there are a SRO of $2-5 \AA$, a medium-range order (MRO) of $5-20 \AA$ and a LRO at distances exceeding $20 \AA[87,88]$. In the case of covalent materials, in which a directed chemical bonding is dominant, a SRO can be characterized in terms of the well-defined coordination polyhedra, which, in many cases, appear to concur with the unit cells. The definition of a MRO is more contentious and it is helpful to subdivide MRO into 3 subcategories. At the shortest length scale $(\sim 5 \AA)$, a near-MRO describes the connections among the coordination polyhedra. At the next length scale ( $5-8 \AA$ ), an intermediate MRO can be associated with correlations between pairs of preferred dihedral angles for neighboring bonds. Finally, on a yet larger length scale ( 8-20 $\AA$ ), a far-MRO can be associated with the total dimensionality of the covalently bonded amorphous network. Thus, characterizing the nature of MRO in disordered solids is very important for understanding their structure. Fig. 1 represents an excellent visual demonstration of the differences between a SRO and a MRO[89]. Farther details on this topic are available in literature[87,88].

In covalent solids, bond angles and bond lengths, as well as a number of the nearest neighbors, are all part of the appropriate bonding scheme. Thus, due the nature of chemical bonding, even the truly amorphous materials have some structural SRO and, perhaps, some MRO. For example, MRO regions of $\sim 15 \AA$ in dimensions and comprising about 100 atoms have been directly observed in amorphous carbon[90]. Some order in two-dimensional projections of thin amorphous three-dimensional structures was found[91]. Besides, covalent amorphous solids were found to exhibit a MRO at length scales up to $20 \AA$ or so[88]. Such MRO clusters are called paracrystals[86]. These paracrystals have a crystalline topology but the atomic positions are highly distorted from those of a perfect crystal. However, in solids there is a serious problem of very small particles. Specifically, if the crystal sizes are extremely small, it is difficult to make a distinction between the truly amorphous and crystalline solids. Namely, if a powder consists of tiny perfect crystals with dimensions of $2 \mathrm{~nm} \times 2 \mathrm{~nm} \times 2 \mathrm{~nm}\left(8 \mathrm{~nm}^{3}\right)$ or less, both this powder and any bulk materials prepared from this powder (e.g., by compaction) will be amorphous, just due to the case their sizes are below the minimal value of LRO. Additionally, in very small crystals a large fraction of the atoms are located at/or near surface. Relaxation of the surface and various interfacial effects distort the atomic positions, decreasing the structural order. Thus, even the most advanced structural characterization techniques, such as X-ray, neutron and electron diffraction, as well as transmission electron microscopy (TEM), have difficulties in distinguishing between the amorphous and crystalline structures on these length scales[83,92].

Many studies revealed that the majority of solids could be found or prepared in an amorphous state. For example, cooling strongly reduces atomic and/or molecular mobility. Thus, in principle, given a sufficiently high cooling rate, any liquid can be transformed into an amorphous solid. As cooling is performed, the material changes from a super-cooled liquid, with properties one would expect from a liquid state material, to a solid. The temperature at which this transition occurs is called glass transition temperature. If a cooling rate is faster than the rate at which atoms and/or molecules can be organized into a more thermodynamically favorable crystalline state, then an amorphous solid will be formed. In contrast, if atoms and/or molecules have a sufficient time to be organized into structures with two- or threedimensional order, then a crystalline (at least, a semi- crystalline) solid will be formed. Furthermore, in many cases amorphous materials can be produced by additives, which interfere with the ability of the primary constituent to crystallize. For example, addition of soda to melted silicon dioxide results in amorphous window glass and addition of glycols to water results in a vitrified solid[83]. More to the point, amorphization of many solids might be achieved by 
applying mechanical forces, e.g., by intensive milling[93, 94], as well as by irradiation[95,96].

From a thermodynamic point of view, amorphous materials are at best metastable. Given a sufficient time, they tend to transform to crystalline phases that are thermodynamically more stable. Interestingly, but when an unstable crystalline solid is transformed to an amorphous phase, this transformation frequently exhibits features that are associated with ordinary melting. Namely, amorphization frequently begins at grain boundaries, surfaces or other defect sites, as does ordinary melting. Further, as the transformation proceeds, a sharp interface that separates the amorphous materials from the untransformed crystalline material is always observed[82].

\section{Amorphous Calcium Orthophosphates (ACPs)}

\subsection{History}

According to E.D. Eanes[20], the history of ACPs looks as this: "In 1955, Robinson and Watson[97] were the first to suggest that a substantial portion of newly formed mineral in young bone was not crystalline. Instead, they described this early mineral as being more similar in character to an amorphous-like precipitate they had prepared in a study on synthetic HA[98]. This precipitate, which appeared initially in their synthesis when sufficiently concentrated solutions of $\mathrm{CaCl}_{2}$ and $\mathrm{Na}_{2} \mathrm{HPO}_{4}$ were mixed at room temperature and neutral $\mathrm{pH}$, had as its most distinctive features an extremely fine, non-crystalline texture when examined by TEM and no discernable electron diffraction pattern. This latter feature led them to infer that the considerably more diffuse electron diffraction pattern of newly formed bone mineral as compared to more mature bone mineral, although still apatitic in character, indicated the presence also of an amorphous component"[20].

However, A.L. Boskey[19] has reported another story: "In 1964, Dr. Paul Tannenbaum, a graduate student in periodontics at Columbia, and a research assistant in Dr. Posner's laboratory at hospital for special surgery, was studying the effect of fluoride on apatite crystal size. He prepared a synthetic apatite by mixing high concentrations $(\sim 30 \mathrm{mM})$ of calcium chloride and $(\sim 20 \mathrm{mM})$ sodium acid phosphate in buffer, and, being anxious to confirm that the precipitate which formed was apatite, pelleted it by centrifugation, dried it with acetone and placed it on a holder for analysis by wide-angle X-ray diffraction. The pattern obtained (Fig. 2, bottom) was broad and diffuse, with a maximum at $\sim 30^{\circ} 2$ theta, had no features, and was clearly not apatite. Dr. Posner suggested that Dr. Tannenbaum did not have the settings correct on the X-ray diffractometer, but since it was late on Friday, decided to correct the settings on Monday. On Monday, the sample, which had been left on the diffractometer over the weekend, was again subjected to X-ray diffraction analysis, but now the pattern had the appearance of a poorly crystalline apatite (Fig. 2, middle). Dr. Tannenbaum was certain that the settings on the diffractometer were not different from those he had used previously. Instructed by Dr. Posner to repeat the experiment, he observed the same phenomenon. Immediately after being mixed, the precipitate formed was amorphous, while after several hours, it converted to poorly crystalline apatite. It seemed plausible to Dr. Posner that were such an "amorphous" material (i.e., one that did not give a crystalline diffraction pattern) present in bone, along with the apatite, it might account for the broad diffraction pattern of bone mineral"[19]. One should stress, that both L.C. Chow, et al.,[99] and E.D. Eanes[100] published corrigenda to this story by Boskey.

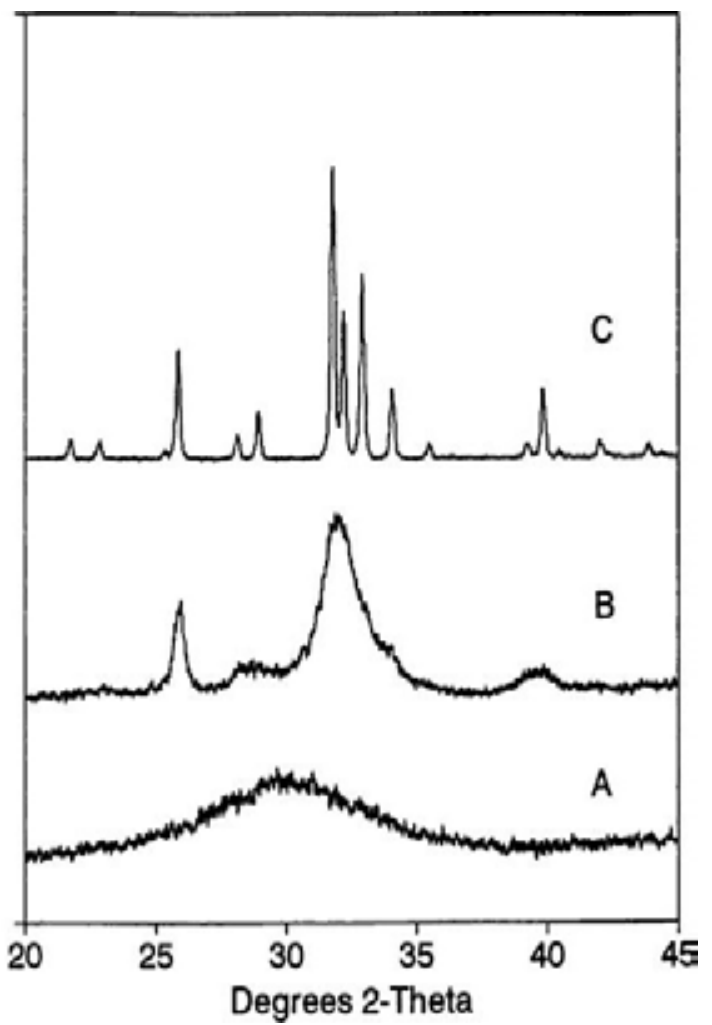

Figure 2. Comparison of X-ray diffraction patterns $\left(\mathrm{Cu} \mathrm{K}_{\alpha}\right.$ radiation, = $0.154 \mathrm{~nm}$ ) of synthetic ACP (bottom), poorly crystalline CDHA (middle) and well crystalline HA (top). The intensity values of the top pattern have been multiplied by a factor of 10 , accounting for a high noise level

In 1960's, both X-ray diffraction and infrared spectroscopic techniques were used to obtain a quantitative estimate of the amorphous content of bone mineral and then, based on the methods used in polymer chemistry, an algorithm to estimate the ACP amount in bones was developed[101-103]. Early X-ray diffraction estimates indicated the presence of $30 \%$ or more of a non-crystalline mineral in bones of several animal species. Later estimates by X-ray radial distribution analysis placed the upper limit of 10\% ACP in bones and brought into question whether all $\mathrm{X}$-ray amorphous mineral of bones was truly non-crystalline[17,104-107]. However, further studies by higher-resolution techniques have shown that $\sim 99 \%$ of the mineral in bone is a poorly crystalline ion-substituted CDHA of a biological origin[19].

Morphological evidence establishing the extent of ACP in 
skeletal tissues of mammals is equally ambiguous. Although some studies[97,108-112] report a presence of small spheroidal particles atypical of crystalline material, primarily in actively metabolizing regions, most TEM studies of bones do not even mention finding such possibly amorphous structures. Furthermore, during ageing, the amount of ACP in bones and teeth of mammals decreases while the crystalline forms of biologically formed ion-substituted CDHA increases during early stages of formation[3,11]. Since both physical and morphological evidences for ACP in skeletal tissues of mammals have been difficult to establish directly, much of our progress in clarifying the possible roles of ACP in biogenic calcification has come from both synthetic and in vitro studies[20].

\subsection{Preparation}

\subsubsection{Wet-chemistry}

Already in early 1970's the researchers established that the final and stable product of a reaction between calcium and orthophosphate salts in neutral or basic aqueous solutions was crystalline stoichiometric HA. However, the stoichiometric well crystalline HA might be prepared at elevated temperatures only; thus, in the vast majority cases, in aqueous solutions CDHA is formed instead. Furthermore, during CDHA precipitation, over a broad range of the solution conditions, an ACP precursor phase is often formed [113-123], in some cases, via a short intermediate stage of OCP formation[124,125]. Data are available that CDHA crystallization from ACP simply involves a LRO increase in the structure[126]. One should stress, that already in the mid of 1970's ACP was found to be not the mandatory precursor to CDHA. Namely, in dilute aqueous solutions CDHA was found to precipitate without going through an ACP precursor[126]. Afterwards, a model was developed to illustrate factors influencing the nature of non-stoichiometric amorphous precursor phases precipitating in highly supersaturated solutions[127].

The basic approach to synthesize ACP still consists of a spontaneous precipitation by mixing concentrated aqueous solutions of calcium and orthophosphate ions, first developed in 1953 by Watson and Robinson[98]. Another commonly used method is to prepare an acidic (pH within $0-4)$ sub-saturated aqueous solution of a calcium orthophosphate salt (e.g., DCPD, MCPM) and afterwards to induce precipitation by a rapid addition of a strong base (e.g., $\mathrm{NaOH}, \mathrm{KOH}$, $\mathrm{NH}_{4} \mathrm{OH}$ ) to reach the desired solution $\mathrm{pH}$, usually within 10 $-12[128]$. Vigorous mixing is highly desirable. By means of both approaches, various types of ACPs have been prepared from solutions encompassing a wide range of $\mathrm{pH}$ (from $\sim 6.5$ to $\sim 13$ ), $\mathrm{Ca} / \mathrm{P}$ ionic ratios (from $\sim 0.1$ to $\sim 10$ ), calcium and orthophosphate concentrations (from $\sim 0.002$ to $\sim 1 \mathrm{~mol} / \mathrm{l}$ ), as well as at temperatures within $0^{\circ} \mathrm{C}$ to $50^{\circ} \mathrm{C}$. However, the $\mathrm{Ca} / \mathrm{P}$ ratio of the mixing reagents (classically, $\mathrm{Ca}\left(\mathrm{NO}_{3}\right)_{2} \cdot 4 \mathrm{H}_{2} \mathrm{O}$ and $\left.\left(\mathrm{NH}_{4}\right)_{2} \mathrm{HPO}_{4}\right)$ is typically kept within $1.50-1.67$, while a basicity of the mixing solutions is frequently created by $\mathrm{NH}_{4} \mathrm{OH}$ addition[48,116,128-132]. At acidic $\mathrm{pH}$, crystalline calcium orthophosphates normally are precipitated. However, in presence of stabilizers (magnesium and/or citrates), ACP could be precipitated at solution $\mathrm{pH}$ within 6.0 - 6.5[133]. No information on ACP precipitation from even more acidic aqueous solutions has been found in literature. The obtained precipitates should be collected shortly after the preparation (the sooner, the better), because in aqueous media ACP is spontaneously converted to the crystalline calcium orthophosphates, mainly to CDHA $[116,134]$. Furthermore, it was shown that the final calcium orthophosphate (a dry powder) would be amorphous if, beside the appropriate key factors of the synthesis (a high concentration of reagents, a basic solution $\mathrm{pH}$, a rapid mixing and a low temperature), both a high addition rate and a mandatory freeze-drying of the precipitates were employed[40,116,132,135].

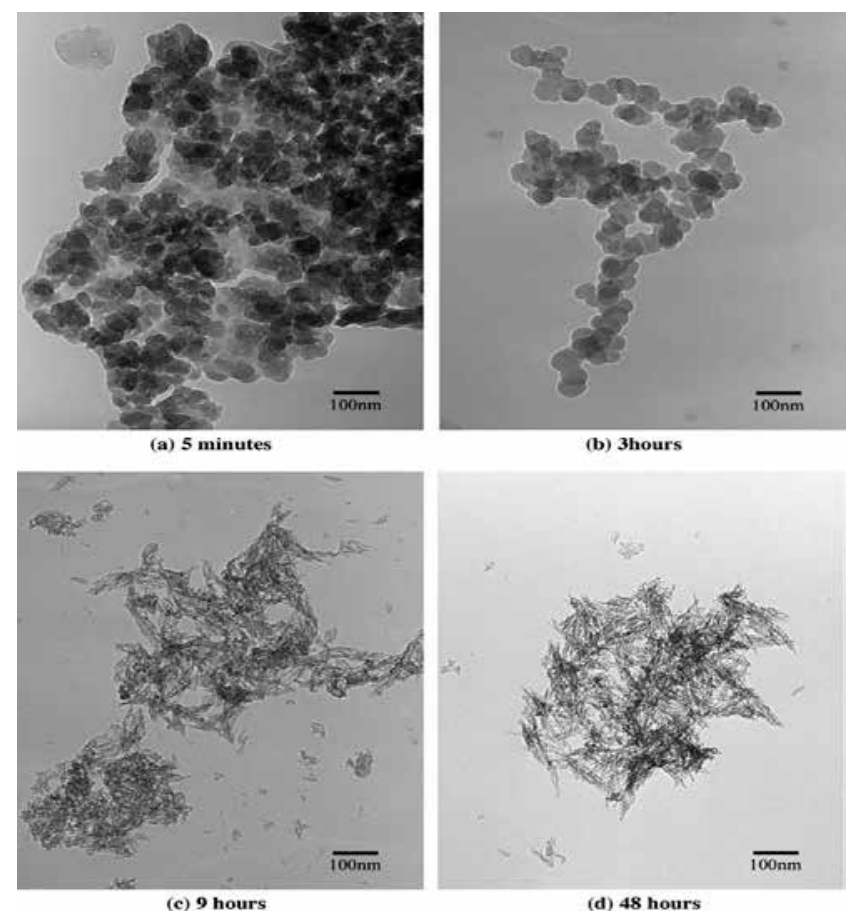

Figure 3. Bright field transmission electron micrographs of ACP $\rightarrow$ CDHA transformation at reaction times of (a) $5 \mathrm{~min}$, (b) $3 \mathrm{~h}$, (c) $9 \mathrm{~h}$, (d) $48 \mathrm{~h}$. Reprinted from Ref.[136] with permission. Another set of electron micrographs of ACP $\rightarrow$ CDHA transformation might be found in Ref.[256]

In all wet-precipitation techniques, the amorphous precursors, although related to the final CDHA phase, are differed from the final phase in atomic structure, particle morphology and stoichiometry. For example, the X-ray diffraction pattern of ACP (Fig. 2, bottom), if compared to those of CDHA (Fig. 2, middle) and HA (Fig. 2, top), shows a single and a very broad and diffuse diffraction peak with the maximum at $\sim 25^{\circ} 2$ theta, typical for amorphous materials, which lack the atomic LRO characteristics of all crystalline materials, including HA[104]. The precipitated ACP phases appear to be spherical (Figs. 3 a and b) in an electron microscope (diameter ca. $30-100 \mathrm{~nm}$ ), unlike the needle-like crystals of CDHA (Figs. $3 \mathrm{c}$ and d). The solution $\mathrm{pH}$, concentration of the mixing reagents and a preparation temperature all affect the ACP particle sizes; namely, a 
higher supersaturation produces smaller ACP particles[129]. Although ACP can be prepared with a $\mathrm{Ca} / \mathrm{P}$ molar ratio as low as $\sim 1.2$ (at low pH - see Fig. 4) or as high as 1.7 (at high supersaturation), the departure from a $\mathrm{Ca} / \mathrm{P}$ of $\sim 1.5$ has been shown to be due to surface-adsorbed soluble phases those can be washed away or to occluded Ca, respectively[104].

Besides, ACP powders might be prepared by spray drying of acidified aqueous solutions of soluble calcium orthophosphates[348].

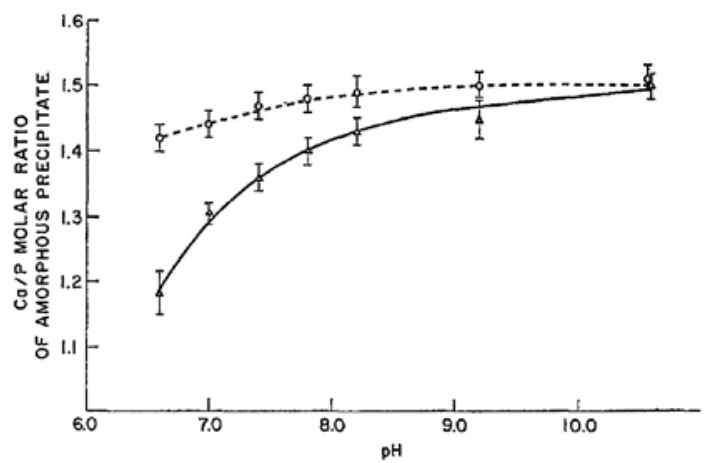

Figure 4. Ca/P molar ratios of washed (dashed line) and unwashed (solid line) ACP precipitates as a function of their formation $\mathrm{pH}$. Reprinted from Ref.[137] with permission
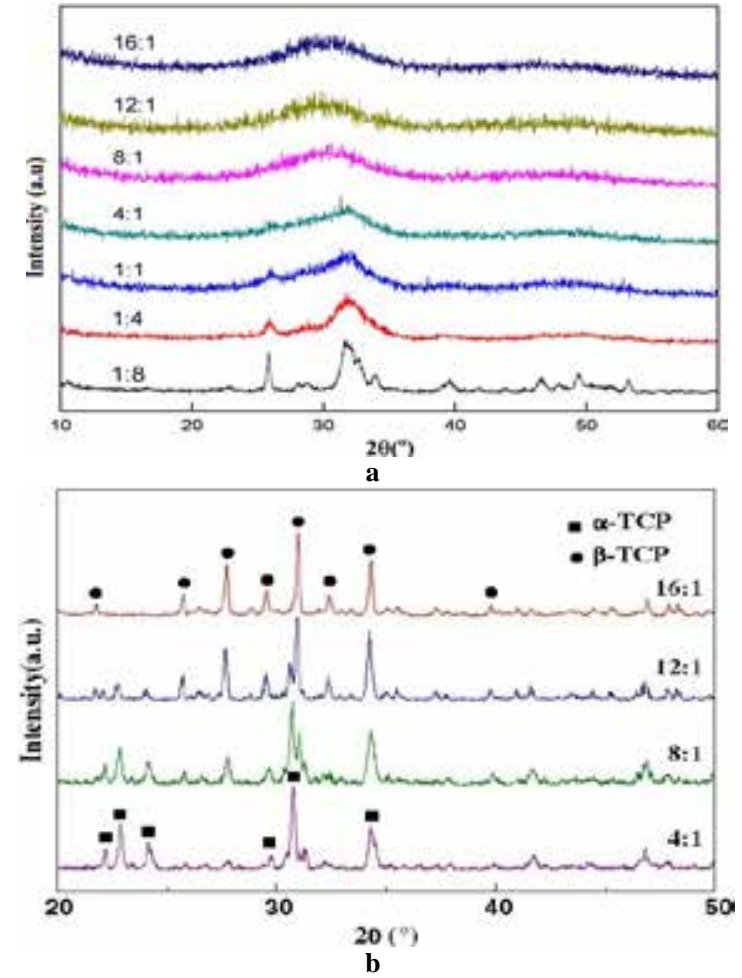

Figure 5. X-ray diffraction patterns of: (a) freeze-dried precipitates prepared from aqueous solutions containing different amounts of polyethylene glycol. Please, note a shift of the center of the broadened peak from $\sim 32^{\circ}$ toward $\sim 31^{\circ}$ with increasing polyethylene glycol/Ca molar ratio, which implies some structural differences in the resulting ACPs; (b) heat-treated $\left(800^{\circ} \mathrm{C}\right)$ ACPs prepared from aqueous solutions containing different amounts of polyethylene glycol. Reprinted from Ref.[150] with permission

\subsubsection{Non-aqueous Solutions and Solvents (sol-gel)}

Besides, ACPs might be easily prepared in either non-aqueous or solvent + water media[72,131,138-152]. The presence of organic compounds and/or solvents results in decreasing of a dielectric constant. Therefore, all ions in solutions appear to be less solvated than those in water. The consequence of this is a strong decrease of solubility and an increase in precipitation kinetics, which simplifies amorphization[153]. Furthermore, in such systems, complexes of calcium with organic agents can be formed. This favors ACP formation, which is attributed to the coordinated complexing agents remaining in the structure of ACP[144]. The influence of the presence of organic solvents to the amorphization degree of precipitated calcium orthophosphates is well illustrated in Fig. 5a. In some cases, incorporation of organic compounds into ACPs has been detected[131,150]. Interestingly, but a replacement of a freeze-drying stage of a wet ACP precipitate by an oven drying at $80{ }^{\circ} \mathrm{C}$ resulted in its transformation to CDHA[139]. This process was ascribed to an internal hydrolysis of a part of orthophosphate ions of ACP to those of CDHA according to the schemes[139, 154]:

$$
\begin{gathered}
\mathrm{PO}_{4}{ }^{3-}+\mathrm{H}_{2} \mathrm{O} \rightarrow \mathrm{HPO}_{4}{ }^{2-}+\mathrm{OH}^{-} \\
\mathrm{Ca}_{9}\left(\mathrm{PO}_{4}\right)_{6}+\mathrm{H}_{2} \mathrm{O} \rightarrow \mathrm{Ca}_{9}\left(\mathrm{HPO}_{4}\right)\left(\mathrm{PO}_{4}\right)_{5} \mathrm{OH}
\end{gathered}
$$

\subsubsection{Mechanical and Pressure-induced Techniques}

In addition to the aforementioned solution-based methods, various types of ACPs might be prepared by dry chemical techniques. For example, an ACP was prepared using a mechano-chemical method involving a dry mixture of DCPD and $\mathrm{Ca}(\mathrm{OH})_{2}$ reactants with a Ca/P ratio of 1.67[155]. Other authors have shown that a prolonged high-energy ball milling of either $\alpha$-TCP, $\beta$-TCP powder in ethanol or a dry mixture of ACP and DCPD powders lead to ACP formation after $24 \mathrm{~h}[156-158]$. Furthermore, prolonged high-energy ball milling of TTCP was found to result in a mechanical activation with the formation of undisclosed nanocrystalline and/or amorphous domains within the compound[159]. However, there is a non-negligible risk of powder contamination (ball wear) when using this processing route over extended periods to obtain an ACP[31]. In addition, a crystalline to amorphous transition has been detected for various calcium orthophosphates at very high (up to $10 \mathrm{GPa}$ ) pressures (Fig. 6)[160,161,347].

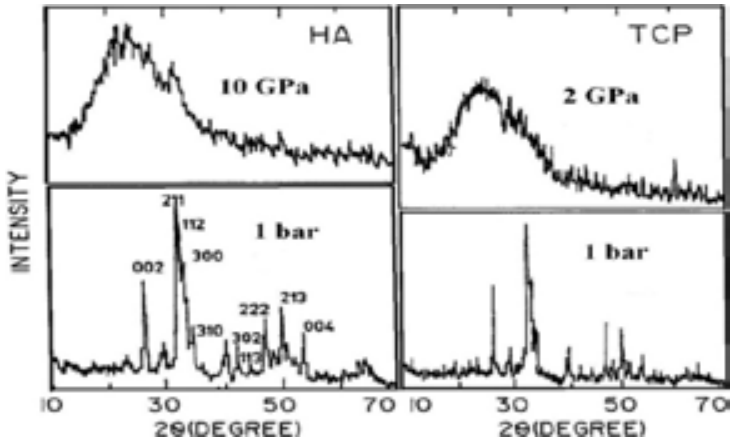

Figure 6. Effect of pressure on X-ray diffraction patterns of HA and hydrated TCP at 1 bar and high pressures. Reprinted from Ref.[161] with permission

3.2.4. Thermal 
Furthermore, ACPs might be prepared using high energy processing at elevated temperatures. This method is based on a rapid quenching of melted calcium orthophosphates occurring, e.g., during plasma spraying of HA[162-174,349]. A plasma jet, which possesses very high temperatures (5000 $20000^{\circ} \mathrm{C}$ ), partly decomposes HA. Furthermore, there is an opinion, that thermal spraying produces the amorphous phase, not only due to the high cooling rate but also to the removal of hydroxyl ions which make it more difficult for the crystalline phase to form[167]. This generally leads to a mixture of calcium orthophosphate phases with variable compositions, often containing impurities, which is not convenient for preparation of pure ACPs. Interestingly, but the amorphization degree of the plasma sprayed HA coatings appeared to correlate with the presence of vacancies of hydroxyl ions in the structure of HA: the more vacancies were present in the apatite structure due to missing hydroxyl sites, the more amount of ACP was present in the resultant coatings[166]. This might be due to the fact that particles resident in plasma for a longer period of time lose more structural water. Other studies have shown more amorphous phase located adjacent to the substrate and a gradient tending towards a lower ACP content at the top of the coating[31].

To summarize, the amorphous phases in plasma sprayed HA coatings are in intimated mixtures with both crystalline calcium orthophosphates and other compounds, such as $\mathrm{CaO}$ [9], and up to now nobody has ever succeed to extract ACPs from the blend. However, the amorphous regions in plasma sprayed HA coatings might be mapped using a scanning cathodoluminescence microscopy technique[170]. Furthermore, due to a number of uncertainties, a reproducibility of such experiments is poor; thus, the plasma spaying technique is not considered as a valuable method to produce ACPs. A flame spray synthesis, when a liquid precursor solution is fed through a capillary into a burning methane / oxygen supporting flame, seems to be more preferable to produce ACPs at high temperatures[175,176]. Further details on and additional examples of ACP preparation might be found in literature[31].

\subsubsection{Irradiation}

Just a few studies are available on the amorphization of calcium orthophosphates (up to now, apatites only) by irradiation[177, 178]. However, due to the obvious risks caused by the induced radioactivity, this amorphization approach is highly unlikely to be ever used to prepare calcium orthophosphates for biomedical applications. Unfortunately, it remains unclear in what extent the structures, compositions and properties of ACPs prepared by various production approaches might be mutually compared.

To conclude the preparation part, one should briefly mention on an interesting attempt to precipitate separately hydroxyapatites of $\mathrm{Mg}, \mathrm{Ca}, \mathrm{Sr}$ and $\mathrm{Ba}$ from basic supersaturated orthophosphate solutions containing a 10: 6 divalent cation $/ \mathrm{PO}_{4}$ molar ratio[179]. In the cases of $\mathrm{Mg}$, Ca and $\mathrm{Sr}$, the first precipitated phase had a $3: 2$ ratio (i.e., that of a
TCP), while only Ba went directly to the stable $10: 6 \mathrm{HA}$ phase. Furthermore, the precipitated magnesium orthophosphate was amorphous and remaining in the mother solution did not convert to a Mg-deficient HA. The precipitated calcium orthophosphate formed ACP, which converted to CDHA by a solution-mediated autocatalytic mechanism[130]. The precipitated strontium orthophosphate was not amorphous but poorly crystallized and readily converted in solution to a strontium HA. Thus, the smaller alkaline earth cation systems tended to form the more stable amorphous $3: 2$ compounds[179].

\subsection{Morphology of Precipitated ACPs}

When viewed by TEM, ACP solids precipitated from aqueous solutions usually have a curvilinear appearance rather than the faceted and angular shape of crystalline calcium orthophosphates[180, 181]. However, this curvilinear aspect has only been clearly established for dried ACP. The morphological form of highly hydrated flocculent solids that appear initially in freshly precipitated ACP suspensions is not known. What is observed when drops of these suspensions are placed on carbon-coated grids, excess solution removed and air-dried are irregularly shaped, anastomosing aggregates of low-contrast, disk-shaped particles varying widely in lateral dimensions (from $~ 0.01 \mu \mathrm{m}$ to $5^{+} \mu \mathrm{m}$ ) [181, 182]. These highly flattened particles represent collapsed, de-solvated residues of the initial wet ACP flocculates.

As ACP suspensions age, high contrast particles with a more spherical aspect begin to appear, initially evolving as bud-like extensions from the disks[181, 182]. With time, these spherical forms become the dominant shape for ACP. Although generally smaller (20 - $300 \mathrm{~nm}$ in diameter) than the disks they supplant, the spherical forms, like the disks, frequently aggregate into irregularly shaped and branching clusters. The progression from disk-shaped to ball-like particles most probably represents a spontaneous desolvation in situ or the initial gel-like flocculates into smaller, denser, less hydrated structures[183]. That the spherules are formed in suspension and are not a drying artifact is supported by the crystallization behavior of ACP preparations. Although the evolution of a spherical morphology would be favored during consolidation as this shape minimizes interfacial tension with the surrounding solution, it also requires that the contracting surface be isotropic. This is possible for uniformly curved surfaces only when the enclosed structure remains non-crystalline while desolvating[20].

\subsection{Chemical Composition}

Nowadays, ACPs should be recognized as a special class of biomedically relevant calcium orthophosphate salts having variable chemical but rather identical glass-like physical properties. Presumably, all calcium orthophosphates mentioned in Table 1 might somehow be fabricated in an amorphous state. Therefore, perhaps, sometime in the future people will deal with an amorphous phase corresponding to the chemical composition of MCPM ("amorphous MCPM"), 
an amorphous phase corresponding to the chemical composition of DCPA ("amorphous DCPA"), an amorphous phase corresponding to the chemical composition of TTCP (“amorphous TTCP”), etc. (in most cases, stabilization procedures will become necessary), as well as with various mixtures thereof. Currently the majority of such compounds remain unknown and, in the available literature, a variety of ACPs is distinguished by the $\mathrm{Ca} / \mathrm{P}$ ratio only. Since the greater part of $\mathrm{ACPs}$ has the $\mathrm{Ca} / \mathrm{P}$ ratio close to 1.5 (see below), a term "amorphous TCP” (ATCP) becomes usual in literature[31,140,154,158,175,184-191]. Other terms such as “amorphous carbonated apatite”[40,192,193], “amorphous $\mathrm{CaHPO}_{4}$ "[140], which is equal to "amorphous DCPA" (Table 1), "amorphous $\mathrm{Ca}_{8}\left(\mathrm{HPO}_{4}\right)_{2}\left(\mathrm{PO}_{4}\right)_{4}$ "[140], which is equal to “amorphous OCP” (Table 1), “amorphous OCP”[142], "amorphous $\mathrm{Ca}_{10}\left(\mathrm{PO}_{4}\right)_{6}(\mathrm{OH})_{2}$ "[194], which is equal to "amorphous HA" (Table 1) and "amorphous dicalcium phosphate"[195] are rare but have been already mentioned. Furthermore, formation of an amorphous phase was detected during a slow dehydration at slow heating rates of brushite (DCPD) and its transformation to monetite (DCPA) and the amorphous phase was regarded as "a highly disordered monetite with some free water trapped in the structure" [350]. One should note, that ACPs with the $\mathrm{Ca} / \mathrm{P}$ ratio $<\sim 1.0$ currently remain unknown.

\subsubsection{Precipitated ACPs}

Although first described in 1953[98], the quantitative chemical studies on the precipitated ACPs were not reported until 1965, when methods were devised to isolate large amounts of unstable solids for analysis. To minimize changing during sample drying, those methods utilized filtration and/or centrifugation to wash excess ions from ACP slurries, then freezing wet ACPs under high vacuum to remove any remaining entrapped solvent by sublimation[128]. Early chemical studies[134,196] on ACPs prepared at $\mathrm{pH}$ 10.5, filtered, washed and lyophilized, showed that the $\mathrm{Ca} / \mathrm{PO}_{4}$ molar ratio was very close to 1.5 , suggesting a TCP composition (as $\left.\mathrm{Ca}_{3}\left(\mathrm{PO}_{4}\right)_{2} \cdot \mathrm{nH}_{2} \mathrm{O}[103,197]\right)$. No $\mathrm{OH}^{-}$ions were found in it. Furthermore, the electron spin resonance spectra of vanadyl $\left(\mathrm{VO}^{2+}\right)$ ions adsorbed on ACP formed under varying conditions also revealed that ACP is either a non-crystalline form of hydrated TCP or a solid solution with the composition of $\mathrm{Ca}_{3}\left(\mathrm{PO}_{4}\right)_{1.87}\left(\mathrm{HPO}_{4}\right)_{0.2}$ [198]. Other researchers reported a stoichiometry of the precipitated ACP more akin to OCP[138, 140, 142, 199-204], DCPA[140] and DCPD[205]; however, with a few exceptions[140, 142] the subsequent terms "an amorphous OCP” and "an amorphous DCPD" were not introduced. Namely, although the Ca/P ratio of early formed ACP phases was varied between 1.35 and 1.38, which was close to that of OCP (Table 1), the authors of Refs.[202-204] used a term ACP2 to explain initial variations in solution $\mathrm{pH}$ during the transformation of ACP into more crystalline phases of OCP and/or CDHA. Further, based on the results of TEM analysis, ACP2 was identified as a separate amorphous phase with a floccular morphology and no electron diffraction pattern, if compared with a spherular morphology of the initially precipitated amorphous phase ACP1[202-204]. The same terms ACP1 and ACP2 were used in another study[145], in which the authors studied ageing of calcium orthophosphate precipitates in methanol at room temperature, finally leading to formation of a nano-sized $\beta$-TCP. Furthermore, at precipitation experiments from aqueous solutions containing polyethylene glycol, two types of ACPs were detected [150]: one with a broadened peak centered at $\sim 31^{\circ}$ and another with a broadened peak centered at $\sim 32^{\circ}$ (Fig. $5 \mathrm{a}$, spectra $16: 1$ and $4: 1$, respectively). According to the authors, the first one was similar to the basic structure of $\beta$-TCP, while the second one was similar to the basic structure of HA[150]. Perhaps, one can mention on amorphous $\beta$-TCP and amorphous HA, respectively. A similar shift of the position of the amorphous maximum but obtained at different aging time of ACP precipitates (Table 2) has been detected in another study[132].

Table 2. Position of the X-ray diffraction amorphous maximum at different aging time of ACP precipitates[132]

\begin{tabular}{|c|c|c|c|c|c|c|c|}
\hline Aging time & $2 \mathrm{~min}$ & $1 \mathrm{~h}$ & $2 \mathrm{~h}$ & $3 \mathrm{~h}$ & $4 \mathrm{~h}$ & $5 \mathrm{~h}$ & $6 \mathrm{~h}$ \\
\hline $2 \theta$, degree & 29.5 & 30.1 & 30.4 & 30.3 & 30.5 & 30.8 & 29.0 \\
\hline
\end{tabular}

Note: The $2 \theta$ values were derived from the profile analysis of the scattering curves. Negligible changes were found for longer aged ACPs. The experimental error \pm 0.5 degrees $2 \theta[132]$

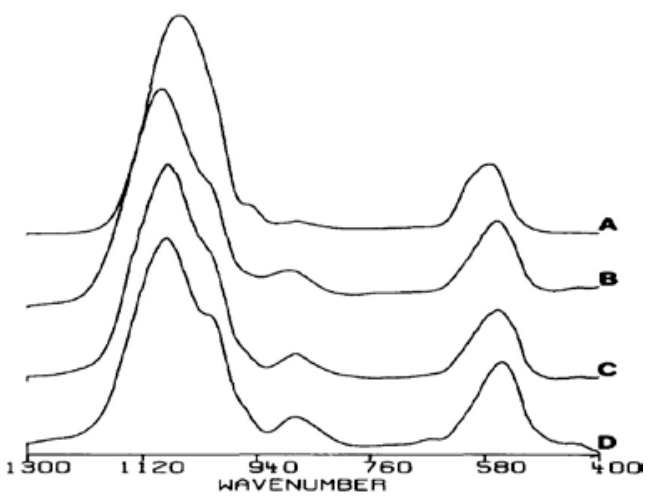

Figure 7. Infrared spectra after baseline subtraction for ACPs prepared at: A - pH 10.0, B - pH 7.0, C - pH 6.5 and D - pH 6.0. Reprinted from Ref. [133] with permission. The complete (from $400 \mathrm{~cm}^{-1}$ to $4000 \mathrm{~cm}^{-1}$ ) infrared spectrum of ACP is available in Ref.[31]

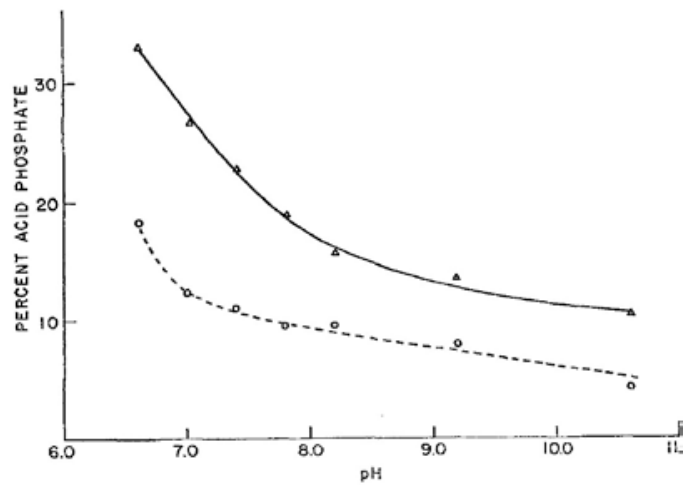

Figure 8. Acid phosphate content (percent of total $\mathrm{P}$ as $\mathrm{HPO}_{4}{ }^{2-}$ ) as a function of $\mathrm{pH}$ for washed (dashed line) and unwashed (solid line) ACP precipitates. Reprinted from Ref.[137] with permission

Additional analyzes of ACPs prepared from aqueous solutions at $\mathrm{pH} \sim 7.4$ at wide variations (from $5: 1$ to $1: 5$ ) in 
starting $\mathrm{Ca} / \mathrm{PO}_{4}$ molar ratios showed that the compositional $\mathrm{Ca} / \mathrm{P}$ ratio decreased only slightly from $\sim 1.5$ due to the presence of small amounts $(<15 \%)$ of $\mathrm{HPO}_{4}{ }^{2-}$ ions[137, 206-208]. This is an indirect confirmation of the existence of an amorphous TCP. The presence of $\mathrm{HPO}_{4}{ }^{2-}$ in ACP is easy to detect by infrared spectroscopy most notably by an absorption peak at about $890 \mathrm{~cm}^{-1}$, due to a $\mathrm{P}-\mathrm{O}(\mathrm{H})$ stretching mode of protonated orthophosphate species (Fig. 7)[133, 140]. Furthermore, in infrared spectra of $\mathrm{HPO}_{4}{ }^{2-}$-contained ACPs there is a large band of a weak intensity near $2300 \mathrm{~cm}^{-1}$, which corresponds to $\mathrm{H}-\mathrm{O}(\mathrm{P})$ stretching in $\mathrm{HPO}_{4}{ }^{2-}$ ions[140]. More to the point, the amount of $\mathrm{HPO}_{4}{ }^{2-}$ in ACP strongly depends on the solution $\mathrm{pH}$ : the lower the $\mathrm{Ca} / \mathrm{P}$ ratio for any given ACP precipitate, the greater is its $\mathrm{HPO}_{4}{ }^{2-}$ content (Fig. 8).

The presence of $\mathrm{HPO}_{4}{ }^{2-}$ ions in ACP has been confirmed by solid-state nuclear magnetic resonance (NMR) technique: the results revealed the presence of $\sim 20 \%$ of $\mathrm{HPO}_{4}{ }^{2-}$ in two ACP samples[209]. Furthermore, orthophosphate units close to water and a third (remained unknown) type of orthophosphate groups were found in the NMR spectra of the ACPs. What's more, substantial differences were noticed between the NMR spectra of two ACP samples, donated by two different research groups[209]. In other studies, two ACP samples of different chemical composition (since they had been prepared at solution $\mathrm{pH}=6.5$ and 10.0 , respectively) were found to give very similar EXAFS spectra[133, 210]. The latter means that a SRO around calcium ions of both ACPs appeared to be very similar; however, the reasons why the $\mathrm{pH}$ differences were not reflected in the calcium environment remained unclear. These experiments confirm the fact that ACPs are not a single chemical compound but represent a special class of amorphous calcium orthophosphate salts. Thus, precipitated ACPs cannot be described by a single chemical formula; a sketch $\mathrm{Ca}_{\mathrm{x}} \mathrm{H}_{\mathrm{y}}\left(\mathrm{PO}_{4}\right)_{z} \cdot \mathrm{nH}_{2} \mathrm{O}$ (Table 1) seems to be the most reasonable element demonstration of this class of calcium orthophosphate salts. Presumably, ACPs with the $\mathrm{Ca} / \mathrm{P}$ ratio exceeding $\sim 1.6$ should also contain some amount hydroxide anions; however, no information on this point has been found in literature. However, a presence of $\mathrm{CaO}$ is frequently detected in ACP-containing calcium orthophosphate coatings prepared by plasma spraying.

Nevertheless, in slightly alkaline aqueous solutions, ACP might have a well-defined chemical composition. For example, there is a finding that ACP slurries over the $\mathrm{pH}$ range $7.4-9.25$ appeared to have a nearly constant solution ion activity product of $\sim 1.6 \times 10^{-25}$ when the solid-phase composition is postulated to be $\mathrm{Ca}_{3}\left(\mathrm{PO}_{4}\right)_{1.87}\left(\mathrm{HPO}_{4}\right)_{0.2}$, i.e. when the local chemical unit in ACP is postulated to have a $\mathrm{Ca} / \mathrm{P}$ molar ratio of 1.45 , with $\sim 10 \% \mathrm{HPO}_{4}{ }^{2-}$, but without $\mathrm{OH}^{-}$ ions[207]. Thus, in spite of the absence of a LRO, this relative constancy in the composition over such a wide $\mathrm{pH}$ range indirectly suggests that ACP should have some well-defined local chemical units. However, at solution $\mathrm{pH}$ exceeding 9.25, ACP does not appear to have a nearly constant solution ion activity product. This breakdown in the solution con- stancy suggests that the solubility-controlling ions of ACP are subtly dependent compositionally on the preparation conditions. Perhaps, at solution $\mathrm{pH}>9.25$ the content of $\mathrm{HPO}_{4}{ }^{2-}$ ions no more remains constant and gradually decreases with $\mathrm{pH}$ increasing[128]. Furthermore, at more acidic $\mathrm{pH}=6.9$, ACP precipitates with $\mathrm{Ca} / \mathrm{P}$ molar ratios as low as 1.15 have been reported[211]. These latter precipitates are extremely unstable and rapidly change over into crystalline DCPD. Again, a term "amorphous DCPD" has not been introduced in that study.

Even after a lyophilization, solution-matured, spheroidal ACP solids still retain 15\% water by weight[197,212]. A temperature programmed description analysis by Sedlak and Beebe indicated that the most part ( 75\%) of this retained water was tightly bound inside the solid, while the rest was a more loosely held surface water with different activation energies of 20.0 and $10.5 \mathrm{kcal} / \mathrm{mole}$, respectively[213]. These results suggest that ACPs do not completely desolvate in solutions but remain partially hydrated with about 3 water molecules per formula unit. Other researchers found that water occurred in regions those were only loosely associated with calcium cations in ACP[5]. Furthermore, when prepared from carbonate-containing solutions, ACPs can readily incorporate carbonate anions[35-40,214,215]. The amount of carbonate incorporated at any given $\mathrm{pH}$ increases with solution carbonate concentration. At a given concentration, carbonate uptake also increases with $\mathrm{pH}$. Incorporating carbonate into ACP does not affect the $\mathrm{HPO}_{4}{ }_{4}{ }^{2-}$ content but raises the $\mathrm{Ca} / \mathrm{P}$ molar ratio. At physiological $\mathrm{pH}$, the carbonate content of ACP precipitated from solutions containing $30 \mathrm{mmol} / \mathrm{l}$ carbonates is $\sim 3 \%$ by weight[182]. These data suggest that ACP, if present in skeletal tissues, would contain appreciable amounts of carbonates, although less than those present in the apatitic phases of bones[215]. Two other ions that readily incorporate into the ACP structure are $\mathrm{Mg}^{2+}[37,44,133,179,216-218]$ and $\mathrm{P}_{2} \mathrm{O}_{7}{ }^{4-}[215,219,220]$. Ions such as $\mathrm{P}_{2} \mathrm{O}_{7}^{4-}$, carbonate and $\mathrm{Mg}^{2+}$ increase the solution stability of ACP and, in the case of the latter two ions, could possibly play an important role in maintaining the presence of ACP in skeletal tissue. In addition, other ionic substitutions are possible; however, such inorganic additives alter the ACP composition, which would enhance the negative effects in the biomedical application of ACP. Besides, with a few important exceptions, ion-substituted forms of ACP [34-47] are not discussed here.

\subsubsection{Other Types of ACPs}

Little is known on the chemical composition of ACPs, prepared by other amorphization techniques. For example, various ACP samples prepared by compressing of several calcium orthophosphates at very high pressures revealed collapses of their initial crystal structures but possible changes in their chemical compositions were not investigated[160,161]. Interestingly, but the authors found that in the region below $550 \mathrm{~cm}^{-1}$ the infrared spectra of DCPD in amorphous phase resembled that of HA in the crystalline phase and conversely the spectra of DCPD in the crystalline 
phase resembles that of HA in the amorphous phase[161]. In the case of milling, calcium orthophosphates were found to become amorphous; however, no additional phases were detected[157,158]. Presumably, this means that during amorphization their chemical composition remained unchanged.

Concerning the ACPs formed in plasma-sprayed HA coatings, the authors of one study reported that "the amorphous phase mostly consists of a dehydroxylated calcium phosphate"[174], which, presumably, meant dehydroxylated HA. If so, the chemical composition of that particular ACP should be close to amorphous OA. The authors of another study considered "that the amorphous phase substance consists of HA molecules" (Ref.[163], p. 227). However, in the next study, the same authors mentioned that "the plasmasprayed amorphous phase is an oxyapatite"[164]. No further clarification has been provided; however, all these authors have come to the conclusion on the apatitic chemical composition of the plasma-sprayed amorphous phases. Besides, these ACPs are definitively anhydrous contrary to the precipitated ACPs.

To conclude the chemical part, one should mention on solubility of ACPs. Due to the chemical variations, this value cannot be measured precisely (Table 1). Several different solubility products have been proposed for various ACPs and the interested readers are referred to Table 1 of Ref.[31] for the details.

\subsection{Structure}

In general, determination of the atomic structure of amorphous solids is a non-trivial task. As the structure can be defined essentially only in terms of unit-cells containing an infinitely large amount of atoms (as there is no LRO periodic symmetry), a statistical description appears to be unavoidable. Thus, the structure of a particular amorphous solid can never be determined unambiguously and this uncertainty is compounded by the fact that the structure of a non- crystalline material often depends on the specific details of preparation techniques[88]. Furthermore, the chemical composition, namely the $\mathrm{Ca} / \mathrm{P}$ ratio, of ACPs varies a lot $(1.2<\mathrm{Ca} / \mathrm{P}$ $<2.2$ - see Table 1), which makes the task even more complicated. The latter results in the fact that different samples of ACP possess diverse properties and the data found for one particular sample appear to be inapplicable to other ACP samples. A possible solution of this problem seems to be in a wide recognition of the fact that ACP is not a single chemical compound but represents a group of calcium orthophosphates having diverse physical and chemical properties. In other words, depending on the $\mathrm{Ca} / \mathrm{P}$ ratio and/or other properties, first of all, any particular sample of ACP must be ascribed to the existing crystalline phase from Table 1 and only afterwards any structural investigations should be performed. This is the only way to succeed in clarification of the ACP structures from experimental measurements in future. Current state-of-the-art on the structure of ACPs is given below.

The first quantitative studies on a synthetic ACP were done in the mid of 1960's on a material precipitated at $\mathrm{pH}$ $10[134,196]$. As Watson and Robinson found at neutral $\mathrm{pH}$, the initial phase that spontaneously formed immediately upon mixing concentrated alkaline Ca- and $\mathrm{PO}_{4}$-containing solutions was structurally non-crystalline[98]. The X-ray diffraction pattern of this rapidly precipitated phase showed only two very broad and diffuse peaks, typical for substances that lack the periodic LRO[196]. The extreme diffuseness of the synthetic ACP pattern also provided a basis for interpreting the reduced intensity of the apatitic X-ray diffraction patterns of bones as being due to the mineral having an amorphous component[101]. The diffracted X-ray energy from this component was so uniformly dispersed that it could not be separated from the subtracted background intensity[20].

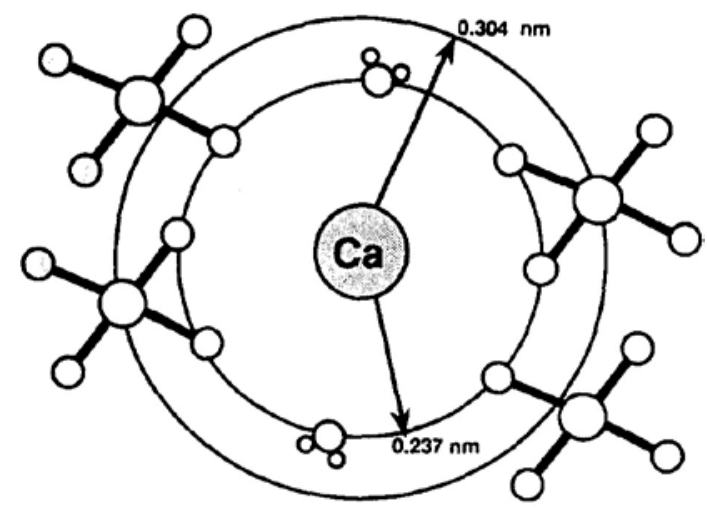

Figure 9. Diagrammatic representation of the SRO structure of four phosphate tetrahedra and two water molecules about calcium ions in an acidic ACP, calculated using the DCPD shell model. The positions of hydrogen atoms are not determined. Reprinted from Ref.[227] with permission

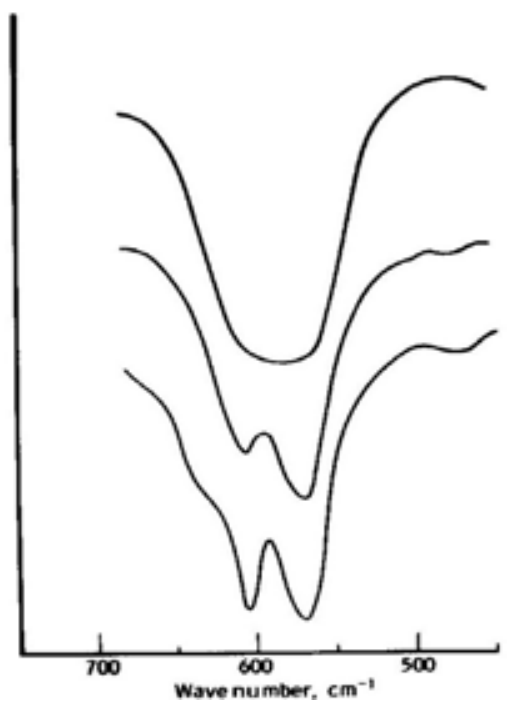

Figure 10. Fragments of the infrared spectra of ACP (upper), CDHA (middle) and HA (lower). Reprinted from Ref.[129] with permission

Initially, there were suggestions that a synthetic ACP was, in fact, HA of such small crystal dimensions that its X-ray diffraction pattern was widely broadened to appear amorphous in character. However, calculated X-ray diffraction patterns assuming that ACP consisted of small groups of HA 
unit cells, or even a single HA unit cell, did not match the observed ACP diffraction data[221]. The NMR spectra of ACP are also sufficiently different from those of HA to suggest that they do not have the same structural motif[222]. Then, a probability that ACP was structurally distinct from HA led to a study of this material by the X-ray radial distribution method, which showed that its characteristic diffuseness resulted from a breakdown in atomic LRO within the interior of the synthetic ACP[223-225]. The major peak positions were found to occur at distances of $2.55,3.75$ and $6.40 \AA$ with an evidence of a peak at $2.9 \AA$ [223]. Furthermore, any orderly atomic arrangements did not extend beyond $\sim 0.95 \mathrm{~nm}$ in diameter that corresponded to the smallest values of a far-MRO. A contiguous periodic regularity in the distribution of these domains typical of crystalline materials was absent. Extended X-ray absorption fine structure (EXAFS) spectroscopy[116,226] indicated that possible regularities in the local environment around individual $\mathrm{Ca}^{2+}$ ions were even more circumscribed, not extending beyond distances of $\sim 0.3 \mathrm{~nm}$ (Fig. 9). This is a SRO scale. In addition, an infrared analysis showed a similar lack of crystalline order for orthophosphate anions in the ACP structure $[31,129,140,228]$. The method is based on the observation that a splitting of the $\mathrm{P}-\mathrm{O}$ anti-symmetric bending mode at $550-600 \mathrm{~cm}^{-1}$ (Fig. 10) increases as crystallinity increases. This apparent lack of crystalline regularity is one of the striking features of ACP that distinguishes it from other calcium orthophosphates and provides the structural basis for its name[20].

The apparent absence of observable crystalline features in ACPs does not rule out a possibility that ACPs might have a well-defined local structural unit. The compositional constancy of ACPs over a relatively wide range of the preparative conditions suggests an existence of such a core structure[104]. Several lines of evidence, however, indicate that the local unit of ACPs is not a crypto-structural variant of one of the crystalline calcium orthophosphates. For example, although in the majority of cases precipitated ACPs appear to be closest in composition to TCP, in aqueous solutions ACPs transform into either OCP or CDHA but not into TCP. If ACP were a cryptocrystalline TCP, direct growth into observably crystalline TCP by crystal ripening would be expected to occur. However, a possibility that ACP might be a cryptocrystalline forms of CDHA or HA cannot be as easily precluded. Only below $\mathrm{pH} \sim 9$ CDHA can be ruled out for the same reason as TCP. However, even above this $\mathrm{pH}$, the finding that CDHA forms primarily as an outgrowth from the surface of ACP suggests that an in situ ripening process does not occur. Furthermore, dissimilarity in composition rules out ACP as being made up of highly disordered arrays of OCP unit cells. It is equally unlikely that ACP is an orthophosphate-deficient OCP as the structural integrity of the latter depends on a full complement of orthophosphate groups in the unit cell. The finding that the $\mathrm{Ca} / \mathrm{P}$ molar ratio remains relatively constant at $\sim 1.5$ over a relatively wide range of $\mathrm{pH}(7.4-9.25)$ appears to preclude ACP as a cryptocrystalline mixture of OCP and CDHA. Instead of remaining constant, a rise in $\mathrm{pH}$ would expect to increase the overall $\mathrm{Ca} / \mathrm{P}$ molar ratio of such a mixture as the relative proportion of the OCP and CDHA components would shift in favor of the latter[20].

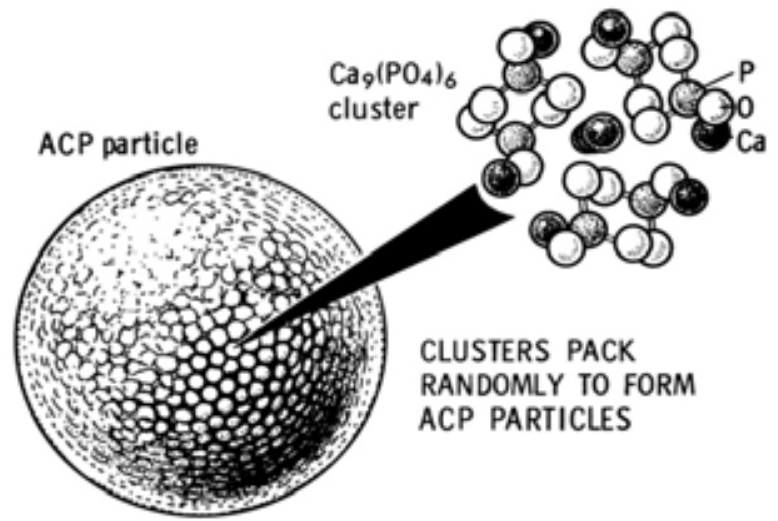

Figure 11. A model of ACP structure. Reprinted from Ref.[106] with permission

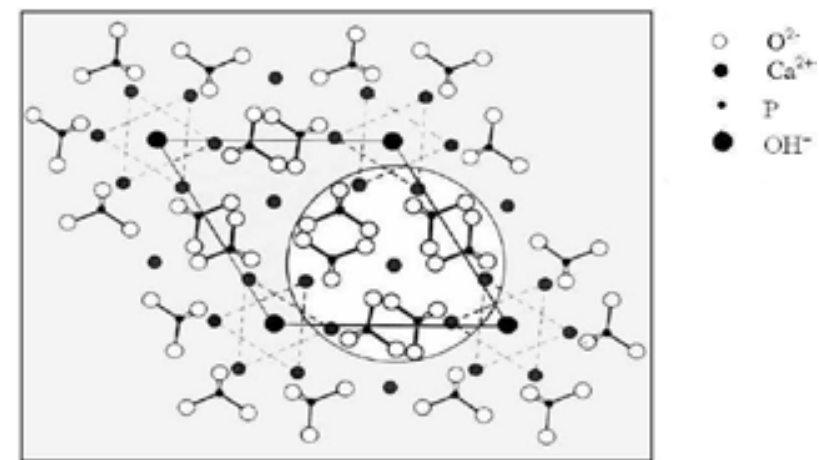

Figure 12. A model of Posner's cluster (in a circle) showing its relationship with the HA crystal structure. Black lines forming a rhomb delimit the borders of one unit-cell of HA. Reprinted from Ref.[31] with permission. A similar relationship is also available in Ref. 258]. This correlation between Posner's clusters and HA structure was first published in Ref.[104]. One should note, that in Ref. 230] another set of atoms of the HA crystal structure has been chosen to represent a Posner's cluster

Based on the relatively constant $\mathrm{Ca} / \mathrm{P}$ ratio of $\mathrm{ACPs}$ formed under varying precipitation conditions, such as different concentrations of calcium and orthophosphate ions, solution $\mathrm{pH}$ and different temperatures, as well as spectroscopic and structural analyzes, Posner and Betts hypothesized that the initial solid phase of ACPs (more precisely, of an amorphous TCP) precipitated in vitro consisted of spherical particles ranging within $300-1000 \AA$ in diameter with water molecules in the interstices[104, 106, 224, 225]. Namely, the defining structural unit of ACP is a spatial subset of the HA unit cell consisting of a central $\mathrm{Ca}^{2+}$ ion coordinated by the oxygens of six surrounding orthophosphate groups, which, in turn, are stabilized by another $8 \mathrm{Ca}^{2+}$ ions spherically distributed around the outer boundary of the subset (Fig. 11). This appears to be a neutral ion cluster of $9.5 \AA$ in diameter, whose composition is expressed by the formula $\mathrm{Ca}_{9}\left(\mathrm{PO}_{4}\right)_{6}$, i.e., 3 times of TCP. Since then, in literature it is defined as a Posner's cluster. It was later suggested that these clusters in fact possessed a $\mathrm{S}_{6}$ symme- 
try[229, 230]. This subset is linearly expanded by $3 \%$ and its radial distribution function is similar to that calculated from the diffuse X-ray diffraction profile of ACP. The authors postulated that at the far-MRO level these slightly enlarged spherical subsets are randomly clustered in ACP particles (Fig. 11) with water filling the intervening spaces[104,224,225]. No data have been found in the references that plasma-spayed ACPs cannot contain Posner's clusters as the structural units; however, undoubtedly, they cannot contain water molecules in the intervening spaces. Interestingly, but the atomic arrangement of Posner's clusters appears to be analogous to that existing in several types of crystalline calcium orthophosphates, such as HA, OCP and $\beta$-TCP. For example, the relationship between the original Posner's cluster and the atomic structure of HA is represented in Fig. 12. However, one must stress, that this is a model only because the real arrangements of the clusters into larger structures are not known yet.

In general, an electrostatic interaction, a hydrophobic interaction and a "cementing" effect of water molecules are among the main factors holding ions of a cluster altogether[231]. Again, a "cementing” effect of water molecules is applied for ACPs precipitated from aqueous solutions only. Theoretical investigations on the stability of different calcium orthophosphate clusters with an increasing number of ions have confirmed that Posner's clusters are the most stable arrangement[232]. The potential energy surfaces associated with $\left[\mathrm{Ca}_{3}\left(\mathrm{PO}_{4}\right)_{2}\right]_{\mathrm{n}}$ clusters were analyzed in details using $a b$ initio calculations for $n$ ranging from 1 to 4 [233]. The energy criteria were found to favor the Posner's cluster, which is the core of the actual structural model of ACP (more precisely, of amorphous TCP). Moreover, the calculations showed that an aggregation of the clusters corresponded to a large energy stabilization whatever the cluster considered[233], which is in agreement with the Posner's hypothesis in which clusters are proposed to be closely packed in the ACP structure. Furthermore, the vibration spectra of ACP have been modeled as well[234]. In spite of the aforementioned, it is not quite clear from what experimental, spectroscopic and/or structural data the cluster model (Fig. 11) has been derived, except the TCP composition. Further, it is not entirely clear whether there are volumetric regions within the large $300-1000 \AA$ particles that are free from the $9.5 \AA$ clusters. In other words, are there some volumetric regions within the large $300-1000 \AA$ particles where the atoms are completely random with no SRO? Moreover, the results of EXAFS analysis indicated that the range of orderly $\mathrm{Ca}-\mathrm{Ca}$ and $\mathrm{Ca}-\mathrm{P}$ interactions in ACP were much shorter than would be predicted from the Betts and Posner model[116,226]. Another weakness in the model is that water only serves to fill the interstices between the HA subsets and is not an essential part of the ACP structure, contrary to the assumptions by Sedlak and Beebe[213]. Both of these weaknesses could possibly be remedied if a smaller spatial domain is carved from a portion of the OCP unit cell that contains a part of the hydration layer. However, this suggestion has not been examined in details. It is also pos- sible, however, that the defining structural unit for ACP is a truly unique entity with no satisfactory crystallographic model. In fact, there is no a priori need for such a model, as the defining unit for ACP would not be constrained structurally by the symmetry requirements for crystalline arrangements. Furthermore, it will also depend on the $\mathrm{Ca} / \mathrm{P}$ ratio. Therefore, ACP could have a structural motif not found or even permissible in any of the crystalline calcium orthophosphates[20].

More to the point, mechanisms of calcium and orthophosphate ion association in aqueous solutions were elucidated by means of quantum and classical molecular mechanics simulations[235]. A special focus was dedicated to the role of the protonation state of orthophosphate ions and depronation of the hydrogenorthophosphate ions appeared to be necessary during crystal growth. According to the simulation results, a triple ion $\left[\mathrm{Ca}^{2+} \cdot .\left(\mathrm{HPO}_{4}\right)^{2-} \cdot \mathrm{Ca}^{2+}\right]^{2+}$ could form in aqueous solutions and subsequently yield another triple ion $\left[\mathrm{Ca}^{2+} . .\left(\mathrm{PO}_{4}\right)^{3-. .} \mathrm{Ca}^{2+}\right]^{+}$by releasing a proton. The latter ion suggested to be the smallest stable aggregate, which contains an entirely deprotonated orthophosphate ion[235]. Some indirect experimental evidences in support of this hypothesis have been obtained recently[236]. Nevertheless, a verification of the aforementioned structural models of ACPs will require details of the chemistry and the processing conditions together with viewing techniques at the atomic scale. Unfortunately, no additional information on the structure of high-temperature ACP phases has been found in the references. Thus, for want of anything better, one is forced to assume, that except of water molecules and possible presence of $\mathrm{HPO}_{4}{ }^{2-}$ ions, all the aforementioned is valid for ACPs presented in plasma-sprayed coatings. Undoubtedly, this assumption should be verified and corrected in future.

To conclude the structural part, determination of the specific surface area of ACPs generally leads to surprisingly low numbers. This might be related to the larger spherical associations of Posner's clusters and the apparent hindrance to nitrogen adsorption of these inner surfaces[189,212].

\subsection{Thermal Properties}

All types of ACP (presumably, except of ones presented in plasma-sprayed coatings) are thermally unstable and sustain neither calcining nor sintering. For example, if precipitated ACPs are heated, first of all, they lose water. Two types of water loss occur, corresponding to loosely bound water molecules adsorbed on the surface of ACP agglomerates and more strongly bound internal water molecules, respectively. The first loss is essentially reversible, whereas the second is mostly irreversible[213,237]. Furthermore, in experiments, where water interactions were minimized by allowing for the escape of volatile components, crystallization of ACP was found to begin at about $530^{\circ} \mathrm{C}[197]$. Below this temperature, the non-crystalline features of ACPs seemed thermally stable. The first crystalline phase to appear was invariably $\beta$-TCP. However, between $600^{\circ} \mathrm{C}$ and $800^{\circ} \mathrm{C}$, depending upon the preparation, $\alpha$-TCP was found to become generally the favored ignition product, even though $\beta$-TCP is normally the 
stable phase up to $\sim 1200^{\circ} \mathrm{C}$. Neither washing + drying procedures employed to isolate the amorphous material, nor the choice of soluble orthophosphate salt used in its preparation, were found to have any significant effect on the thermocrystallization properties of ACP[197]. However, in other studies, both $\alpha$-TCP $[147,175,176,189]$ and carbonated CDHA[141] appeared to be the first detectable crystalline phase at heating of various ACPs to $550-600^{\circ} \mathrm{C}$. Interestingly, but the presence of organic solvents (in that case, polyethylene glycol) at the ACP preparation stage was found to influence the products formed at elevated temperatures[150]. Namely, when the amount of polyethylene glycol was small, $\alpha$-TCP was formed at heating; when the amount of polyethylene glycol was big, $\beta$-TCP was formed at heating; and biphasic $(\alpha-\mathrm{TCP}+\beta$-TCP) formulations were formed when the amount of polyethylene glycol was average (Fig. 5b). Similar effects of both aging time and the solution $\mathrm{pH}$ were also detected[151].

ACPs with Ca/P ratios of 1.00 ("amorphous DCPA") and 1.34 ("amorphous OCP") were found to remain amorphous at heating up to $600^{\circ} \mathrm{C}$, while crystalline compounds $\left(\beta-\mathrm{Ca}_{2} \mathrm{P}_{2} \mathrm{O}_{7}\right.$ in the case of $\mathrm{Ca} / \mathrm{P}=1.00$ and $\alpha$-TCP + $\beta-\mathrm{Ca}_{2} \mathrm{P}_{2} \mathrm{O}_{7}$ in the case of $\mathrm{Ca} / \mathrm{P}=1.34$ ) started to appear at $620^{\circ} \mathrm{C}[140]$. In the same study, ACP with $\mathrm{Ca} / \mathrm{P}$ ratio of 1.51 ("amorphous TCP") were found to remain amorphous at heating up to $\sim 550^{\circ} \mathrm{C}$, while crystalline compounds ( $\beta$-TCP) started to appear at $\sim 600^{\circ} \mathrm{C}$. Interestingly, but heating of a crystalline DCPA (monetite) leads to $\gamma-\mathrm{Ca}_{2} \mathrm{P}_{2} \mathrm{O}_{7}$ and then this phase is transformed at $\sim 750^{\circ} \mathrm{C}$ to $\beta-\mathrm{Ca}_{2} \mathrm{P}_{2} \mathrm{O}_{7}[238]$. Thus, "amorphous DCPA" showed a thermal behavior different from that of crystalline DCPA[140].

Furthermore, crystallization of ACPs is an exothermic process. The heat produced was found to be $\sim 21 \mathrm{~kJ} / \mathrm{mol}$, while the activation energy was $\sim 450 \mathrm{~kJ} / \mathrm{mol}[168]$. Other researchers reported the activation energy values of 440 $\mathrm{kJ} / \mathrm{mol}$ for crystallization of hydroxyl-depleted areas of the amorphous phase to OA and $230 \mathrm{~kJ} / \mathrm{mol}$ for crystallization of hydroxyl-rich areas of the amorphous phase to HA[174]. Therefore, hydroxylated ACP regions were found to crystallize more readily compared to the dehydroxylated ones. A heat of re-crystallization of ACP to HA was calculated to be $\sim 43 \mathrm{~kJ} / \mathrm{mol}$ in still another study[172]. Presumably, such variations are due to the differences in the chemical composition of various ACP samples.

To conclude the thermal part, the results mentioned in this section appear to be additional indirect confirmations of the fact that ACP is not a single chemical compound but represents a special class of calcium orthophosphate salts. Furthermore, as the first approximation and for want of anything better, the first crystalline product formed at heating of a specific ACP sample might become an indicator of its type. Namely, if the first crystalline product was $\beta$-TCP[197], the authors of that study dealt with an "amorphous $\beta$-TCP". Similarly, if the first crystalline product was $\alpha$-TCP $[147,175$, 176, 189], the authors of those studies dealt with an "amorphous $\alpha$-ТСР”, etc. Certainly, this is a hypothesis only, which needs to be investigated and/or verified both theoretically and experimentally in future.

\subsection{Mechanical Properties of ACPs}

Since precipitated ACPs represent highly hydrated flocculent solids (see section 3.3. Morphology of precipitated $A C P s$ ), the mechanical properties could be investigated for ACPs, prepared by mechanical, pressure-induced, thermal and irradiation techniques only. To date, some experimental data on the mechanical properties of thermally prepared ACPs are available only. For example, ACPs were found to have a lower hardness and elastic modulus than HA[239, 240]. Furthermore, nano-indentation experiments revealed that thermally prepared ACPs required about three times more force to initiate cracks if compared to sintered HA, but about nine times more than a single crystal, while crack initiation resistance decreased with increasing grain size. The fracture toughness of ACP was comparable to a single crystal, but higher for nanograined HA[241].

\subsection{Amorphous-to-crystalline Transformations in Aqueous Solutions}

As previously stated, in the vast majority of cases, ACPs are the first solid phases to appear upon mixing of calciumand orthophosphate-containing aqueous solutions at $\mathrm{pH}>7$ and concentrations sufficiently high to produce an immediate precipitation. The spontaneous formation of ACPs is a kinetically driven process. A rapid mixing of highly concentrated solutions creates sufficiently strong stochastic interactions among the ions and they quickly coalesce into irregularly coordinated highly hydrated clusters large enough to separate from solution in a gel-like state before they had a chance to be rearranged into orderly nuclei capable of growth as crystals. This structural arrangement, however, is inherently unstable. In addition to desolvating, ACPs kept in solution eventually disappear, being supplanted by more stable crystalline phases such as OCP or CDHA[20].

Watson and Robinson in their pioneering study on ACP[98] were the first, who observed a transient nature of ACP when kept in contact with its preparative medium. They found that electron diffraction patterns of ACP taken later in the precipitation reaction no longer were diffuse but resembled patterns of a poorly crystalline CDHA. Further investigations revealed that this amorphous-to-crystalline transition was not gradual but occurred rather precipitously. Initially, there is a period of a relative stability, where surfaces of the high-contrast spherules generally remain smooth and regular[181]. However, as seen from the data of Table 2[132], some yet unknown changes occur with the precipitated ACP during this time. Afterwards, the transition follows a sigmoid evolution by the solid phase rapidly progressing from being barely crystalline to where the amorphous features disappear. Once the first crystals appear on the surface of the spherules, the transition proceeds rapidly to completion. Simultaneously, dramatic declines in ionic concentrations of calcium and orthophosphate ions occur in 
the mother solution. The time it takes to reach this amorphous-to-crystalline boundary various considerably with the preparation conditions, being particularly sensitive to temperature and solution $\mathrm{pH}[68,130]$. For example, at $\mathrm{pH} \sim 7.4$, ACP converts five times faster at $37^{\circ} \mathrm{C}$ than at $20^{\circ} \mathrm{C}[242]$. The $\mathrm{pH}$ dependency is somewhat more complex than that for temperature. Namely, at $25^{\circ} \mathrm{C}$ the aqueous lifetime of freshly precipitated ACP is less than $0.3 \mathrm{~h}$ at $\mathrm{pH} \sim 7.4$. It increases to a maximum lifetime of over $9 \mathrm{~h}$ between $\mathrm{pH} \sim 10.0$ and $\mathrm{pH} \sim$ 10.5 , then rapidly decreases until at $\mathrm{pH} \sim 12.8$ the lifetime is nearly as short as that at $\mathrm{pH} \sim 7.4[207,243]$. The solution lifetime of ACP can be greatly extended by inclusion of simple inorganic ions such as $\mathrm{Mg}^{2+}, \mathrm{Zr}^{2+}$, silicates, carbonates and pyrophosphates[40,41,43,133,179,204,216-219,244, 245]. As an extreme example, ACP prepared from $\mathrm{Mg}^{2+}$-containing solutions at $\mathrm{pH}=10.0$ and $32.5^{\circ} \mathrm{C}$ remained in a gel-like amorphous state for up to 20 weeks when the reactant $\mathrm{Mg} / \mathrm{Ca}$ molar ratio was set at 0.2 [179]. Other substances those can increase the stability of ACP in aqueous solutions include $\mathrm{F}^{-}[242,243]$, various polyelectrolytes[67, 68], polyalcohols and polyglycols[131,144,146], phospholipids[246], dentin phosphoprotein[247], phosvitin[220,247], glycochenodeoxycholic acid[248], biomacromolecules such as casein phosphopeptide[69], as well as adenosine di- and triphosphates (but not the monophosphate) [249,250]. On the other hand, excess of $\mathrm{Ca}^{2+}$ ions in the solution accelerates the transformation of ACP into a crystalline CDHA[136]. Interestingly, but collagen, which is the principal matrix protein in skeletal tissues, has no effect on ACP stability[242, 247], while presence of gelatin promotes transformation of ACP into crystalline phases[49]. One should note, that in wet atmosphere solid ACP with $\mathrm{Ca} / \mathrm{P}$ ratio of 1.33 ("amorphous OCP”) was found to re-crystallize into a mixture of CDHA + DCPA[142].

Conversion of ACPs to solid phases with X-ray diffraction characteristics of CDHA has been studied largely in aqueous suspensions $\quad[67,68,72,116,119,121,130,132,136,154,185$, 190,196,218,251-256]. Furthermore, formation of both "pseudo $\beta$-ТCP" and OCP from ACP was detected recently[257]. Transmission electron micrographs of this transformation are shown in Fig. 3. Kinetics of this process can be described by an empirical equation: $\mathrm{dC} / \mathrm{dt}=\mathrm{k}_{1}+\mathrm{k}_{2} \mathrm{C}$, where $\mathrm{C}$ is the fraction of ACP converted into the crystalline phase by time $t, \mathrm{k}_{1}$ is a rate constant associated with the nucleation of the first crystals and $k_{2}$ is an autocatalytic rate constant indicative of the observation that the transition rate is proportional to the mass fraction already crystallized and not to the fraction of remaining ACP[134,196]. Numerical values for $k_{2}$ appeared to be much larger than those for $k_{1}$, reflective of the exponential rapidity of the transition once started[196].

The amorphous-to-crystalline transformation mechanisms of ACPs have not been well elucidated. Chemically, this process is described by equations (1) and (2); while in the reality it might proceed along several pathways. Namely, it might occur as dissolution of ACP and re-precipitation of crystalline phases (e.g., CDHA - see Fig. 13[72])[20,72,118,
$121,128,130,154,190,251,257]$, internal structure rearrangements[136,190,218,229,257-259], development of a LRO without changing the immediate environment of $\mathrm{Ca}[116]$, formation of the crystalline phases either directly within the ACP phases $[149,236]$ or on the surface of ACP particles[256], as well as by self-aggregation and surface-mediated transformations [31]. For example: “... When the density reached a critical value, the random arrangement of growth units became disadvantageous in terms of total free energy, resulting in a sudden regularization of the structure, which was deposited as HA.” (Ref.[229], page 241). Furthermore, Yin and Stott suggested that, in the transformation from ACP to CDHA, ACP needed only to dissociate into clusters rather than undergo complete ionic salvation[260].

Having summarized findings of their own and previously published results by other researchers, Wang, et al.,[236] have depicted a following picture of the main events that take place during the induction period and finally trigger the rapid precipitation of calcium orthophosphates from supersaturated aqueous solutions: "Calcium and orthophosphate ions form pairs and clusters successively in the first few seconds. These ions, pairs and clusters then compose the initial solid phase that is heavily hydrated and contains hydrogenorthophosphates. Growing and aggregating, the solid increases in size and quantity without affecting the solution $\mathrm{pH}$. During the induction period, the solid particles exhibit a steady size distribution, which is around $300 \mathrm{~nm}$ at the early stage and shifts toward $1000 \mathrm{~nm}$ with time. These particles are agglomerates of primary particles of $60-100 \mathrm{~nm}$ in diameter and are originally amorphous in structure. At multiple sites inside a particle, crystalline domains develop from ion pairs and/or clusters by taking up calcium and releasing hydrated proton, possibly through a stage at which the more compact cluster $\mathrm{Ca}_{9}\left(\mathrm{PO}_{4}\right)_{6}$ presents. Since the expansion of crystalline domains consumes surrounding calcium and orthophosphate ions (or their pairs and clusters) and releases hydrated protons, the mechanic strength decreases in the inter-domain regions. Finally, under the action of the shearing strength of the fluid, these primary particles collapse and the liberated crystallites induce the rapid precipitation of calcium orthophosphates, together with the previously trapped hydrated protons in primary particles, resulting in the abrupt $\mathrm{pH}$ drop. Indeed, it is the crystallization at multiple sites inside amorphous particles that finally triggered the rapid precipitation of calcium phosphate from the supersaturated solution." (Ref.[236], pp. 2625-2626).

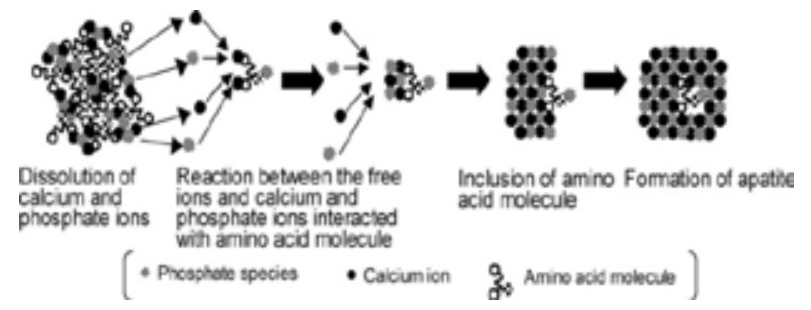

Figure 13. A proposed mechanism of a CDHA/amino acid biocomposite formation from an ACP/amino acid biocomposite. Reprinted from Ref.[72] with permission 
To conclude this part, as ACPs represent a special class of calcium orthophosphates, it is reasonably to presume that various amorphous-to-crystalline transformation mechanisms might exist due to the initial differences of the investigated ACPs. Furthermore, various competitive processes might occur simultaneously and their importance might depend on the conversion conditions. Further details on this topic are available in literature[31, 123].

\section{ACPs in Vivo}

As stated in the introduction, both physical and morphological evidences for the presence of ACPs in skeletal tissue of mammals have been difficult to establish directly and the validity of inferential evidences for their presence and amounts has been the subject of considerable debates. Indirect assessments, such as X-ray diffraction methods, have produced widely varying estimates of the amorphous content of bone mineral, placing it at less than 1\%[19] to more than $\sim 30 \%$ of the total mineral mass, the rest presumably being poorly crystalline ion-substituted CDHA (biological apatite). Even if ACPs only occur at a lower percentage, one would expect TEM to reveal some evidences[9], but as stated earlier, most TEM studies of bones and teeth do not even mention the existence of amorphous-like structures that could be ascribed to ACPs. However, the absence of such structures could have been a negative artifact caused by aqueous dissolution of more labile ACPs during the sample preparation for examination. A few early TEM studies[108,109] that avoided aqueous processing of bone specimens by directly embedding and sectioning freeze-dried material revealed a zone of electron dense, 6 to $20 \mu \mathrm{m}$ diameter spheroidal bodies adjacent to crystal-rich areas of bone tissue. Electron diffraction of these sites revealed a hazy, diffuse pattern similar to that observed by Watson and Robinson[98] in their synthetic, amorphous-like precipitates. Whether or not these spheroidal particles represented ACPs has been debatable but a labile nature of ACPs suggests the need to maintain carefully the anhydrous conditions in preserving this phase in calcified material for examinations[20].

Another possibility that could account for the inability to establish with certainty the existence of ACPs in mammalian bones is that the ACP does not exist as separate particles but, instead, as an amorphous layer on crystals of the poorly crystalline phase of biological apatite. Although there has been no direct evidence for this possibility, similar coatings appear to form in physiological-like solutions seeded with HA[261, 262]. Under these in vitro conditions, the initial accretions appeared to form an amorphous calcium carbonate-ACP coating on the seed crystals. The initial phase also incorporated a small amount of $\mathrm{Mg}^{2+}$ ions from solution that was subsequently released upon the ancillary formation of CDHA crystals. This $\mathrm{Mg}^{2+}$ behavior, consistent with the amorphous-to-crystalline transition, is the most compelling compositional evidence from these studies for the initial coat being an amorphous layer[261].
A proper assessment of the possibility that some of the mineral in skeletal tissues is in a free-standing amorphous state is further complicated by the fact that the minimum ion activity product needed to form ACP de novo in physiological-like synthetic solutions at $\mathrm{pH} 7.4$ is considerably greater than that calculated for serum[126, 263]. If extracellular skeletal fluids were in electrolyte equilibrium with serum, it would appear unlikely that ACPs could form in vivo except possibly as a coating on crystals of biological apatite of bones. Without stronger evidence than that described above, even this possibility, though, is highly speculative. However, there is some evidence that suggests that calcifying bone matrix may be compartmentalized with the establishment of an interior milieu different from that of serum[264]. Unfortunately, it is not known whether such compartmentalization results in an extracellular fluid space capable of initiating de novo ACP formation [20].

Although the general compartmentalization of boneproducing conditions favorable for ACP needs to be further established, a considerable body of evidence suggests that local micro-compartments exist in bones that could allow for ACP development. The most thoroughly studied of these micro-spaces are the membrane-enclosed aqueous cores of matrix vesicles[265, 266]. Most commonly found near osteoblasts in the extracellular regions of rapidly mineralizing embryonic bone, these spherical bodies of cellular origin are the sites of initial mineral formation[267]. Preceding appearance of the first crystals at these sites is an accumulation of calcium and orthophosphate ions within the aqueous cores of the vesicles to levels that far exceed the threshold level for de novo ACP formation[268,269]. Studies with synthetic liposomes confirm that ACP should readily form under such compartmentalized conditions[270]. However, Raman spectroscopic data indicate that ACP in matrix vesicles is not in a pure chemical state but instead calcium and orthophosphate ions are combined in a single-phase complex with lipid and protein moieties found within the vesicles[271]. Also consistent with formation of an amorphous precursor phase are infrared and Raman spectroscopic findings that the first crystals in matrix vesicles are OCP and not CDHA[271,272]. These crystals, in turn, penetrate the enclosing membrane and initiate a chain of crystallization events that appears to trigger the mineralization of the collagenous matrix. Thus ACP, even when present in small amounts, may be an important initiating factor in the calcification of skeletal tissues[20].

Besides the questionable cases of calcified tissues of mammals, ACPs are found in mammalian milk[7,8,73]. Clearly, the presence of the most easily biodegradable calcium orthophosphates in the form of ACPs in milk is necessary to construct skeletons of young organisms.

\section{Biomedical Application of ACPs}

Currently, biomaterials and bioceramics of calcium orthophosphates are available in various physical forms: 
powders, particles, granules, dense blocks, porous scaffolds, injectable formulations, self-setting cements and concretes, implant coatings, as well as composite components of different origin (natural, biological or synthetic) often with the specific shapes, such as implants, prostheses or prosthetic devices[32,33,273]. In principle, all these physical forms should apply to ACPs; however, not all of them have been realized yet. Namely, it is easy to prepare ACPs in a powder form by a wet-precipitation technique (see section 3.2. Preparation); however, manufacturing of other physical forms of ACPs is not so simple. Furthermore, to be used in surgery, all implantable 3D constructions must possess the necessary mechanical properties, which is difficult to achieve in the case of ACPs. For example, both dense blocks and 3D porous scaffolds made of calcium orthophosphates reach their mechanical properties only after sintering at temperatures, exceeding $\sim 1000^{\circ} \mathrm{C}$, which is impossible in the case of ACPs (see section 3.6. Thermal properties). Furthermore, an ACP powder might be easily added as a component to self-setting calcium orthophosphate formulations; however, no cement formulation is known, which results in ACP formation, as the major end product[274,275]. More to the point, ACPs are present as components of various calcium orthophosphate coatings; however, just a few studies are known, in which ACP coatings have been fabricated[276-279].

Not many examples of the biomedical applications of ACPs are currently available. First of all, the majority of cases of plasma sprayed calcium orthophosphate coatings should be excluded because the coatings consist of a complicated mixture of various phases, where ACP is just one of them[9,162-174,349]. Besides, both the amount and the composition of these amorphous phases cannot be wellcontrolled. Even in the case, when ACP was plasma sprayed, the coating was found to be a mixture of a crystalline carbonate-containing apatite phase with considerable amounts of TTCP and trace amounts of $\alpha$-TCP[280]. Thus, these cases may hardly be mentioned as the biomedical applications of ACPs.

There is another type of calcium orthophosphate coatings, obtained by a biomimetic route. Some of them contain ACP as the major component[281-284]. For example, an ACP coating on polyethersulphone plates was prepared by precipitation from a simulated body fluid (SBF) at $35^{\circ} \mathrm{C}$. It took authors 12 days to obtain a $\sim 20 \mu \mathrm{m}$ thick ACP coating and 28 days for a $\sim 50 \mu \mathrm{m}$ thick one[281]. Similar results were obtained in other studies[282,283]. One should stress, that in the vast majority cases, the biomimetic approach presumes application of SBF, which contains ions of sodium, magnesium, potassium, sulfate and hydrogencarbonate; thus, ionsubstituted ACPs are always formed as a result.

Furthermore, ACP coatings can be deposited on titanium using an electrochemical technique at $36^{\circ} \mathrm{C}$ and solution $\mathrm{pH}$ 6.4[284]. The obtained ACP coatings appeared to be unstable and transformed into those of CDHA. By choice of different electrochemical parameters, a homogeneous coating of ACP, CDHA or some intermediate phases could be achieved, thus allowing formation of the coatings with different morphology and solubility[284].

Among the self-setting calcium orthophosphate formulations, there is only one ACP-based composition currently on the market, namely Biobon ${ }^{\circledR}\left(\alpha-\mathrm{BSM}^{\circledR}\right)[285,286]$. This cement comprises a mixture of ACP (50 wt. \%) and DCPD (50 wt. \%) which is mixed with an appropriate amount of aqueous medium (de-ionized water or saline) with a liquid to solid ratio of $0.8 \mathrm{ml} / \mathrm{g}$ at room temperature. An injectable paste is obtained which sets in less than $20 \mathrm{~min}$ at $37^{\circ} \mathrm{C}$. After hardening, the cement is constituted of nanocrystalline CDHA with crystal dimensions close to those in human bones[31]. A similar formulation but additionally containing mechano-activated $\beta$-cyclodextrins has been studied as well[155]. Furthermore, a self-setting ACP + DCPA formulation is known[287]. Besides, ACP might be added as an admixture phase to the standard calcium orthophosphate cement formulations[44,288]. In such cases, addition of ACP resulted in cements exhibited shorter setting times, a compressive strength suitable for non-load-bearing applications and the full conversion to nanocrystalline CDHA. Moreover, ACP-containing formulations demonstrated good cell viability, making them suitable candidates for biomedical applications[288]. More to the point, nano-sized particles of 13, 19 and $40 \mathrm{~nm}$ diameter of amorphous TCP were found to be highly reactive and set to CDHA within minutes, which is much faster if compared with microcrystalline powders of both $\alpha$-TCP and $\beta$-TCP $[187,188]$. A similar approach was reported in other studies[156-158].

Since ACPs do not sustain heating above $\sim 600^{\circ} \mathrm{C}$ (see section 3.6. Thermal properties), a possibility of preparing dense ACP bioceramics was studied using spark plasma sintering technique at temperatures ranging from 150 to $200^{\circ} \mathrm{C}$ with the processing time $<15 \mathrm{~min}$. Unfortunately, the observed mechanical strength of the prepared consolidated disks (sintered for $6 \mathrm{~min}$ at $150^{\circ} \mathrm{C}$ ) was poor[289]. However, an increase in the sintering processing time to $13 \mathrm{~min}$ indicated to a possibility of improving the mechanical properties. The low temperature conditions appeared to be more adaptive to the processing of ACP when compared with the experimental conditions of conventional sintering. However, the physicochemical characterization of the prepared consolidated bioceramics indicated a crystallization of the initial ACP to an apatitic phase with no other detectable crystalline phase[31].

However, the majority of cases of the biomedical applications of ACPs comprise various biocomposites and hybrid biomaterials containing ACP as one of the phases[48-75, 155, 286-314,348]. Several ACP-containing formulations (e.g., Recaldent $^{\mathrm{TM}}$ and Enamelon ${ }^{\mathrm{TM}}$ ) are now commercially available[303]. As can be seen from the references, most of the applications are in dentistry field. In all cases, addition of calcium orthophosphates, including ACPs, imparts both biocompatibility and bioactivity of the biocomposites[294]. For example, to improve cell adhesion, hydrophilic array of ACP was fabricated on a surface of hydrophobic polystyrene[315]. A similar effect was found when coatings com- 
posed of ACP and hyaluronic acid were used[316]. Furthermore, in the acidic oral environment the ACP-containing biocomposites take advantage of the ability of ACPs to release calcium and orthophosphate ions, which potentially can take part in enamel remineralization[51-66,188,292,293, 307,308,310,317-338]. Such ACP-containing biocomposites and hybrid biomaterials might be coatings[296], crèmes [308], nanodimensional fibers[310,314] and cements[155, 290,291]. In dentistry, the ACP-containing formulations are used mainly as anti-cariogenic and/or remineralizing agents [307,308,310,317-338], e.g., in chewing gums[320-322], sugar confections[74], various tooth mousses[323-325], bleaching gels[328,329], various drinks[330,331] or even in milk[335,336]. Furthermore, ACP-containing formulations are used in orthodontics[295-302], as well as they might become effective adsorbents of viruses in water[339].

\section{Conclusions}

ACPs can be both found in living organisms (especially invertebrates) and synthesized in a laboratory. Due to their chemical variability, they should be recognized as a special class of calcium orthophosphates offering a wide variety of compositions. Presumably, all known calcium orthophosphates (see Table 1) might be prepared in an amorphous state; however, not all of them (especially, those with $\mathrm{Ca} / \mathrm{P}$ ratio < 1.1) have been prepared. Furthermore, in the available literature nothing has been found on existence of amorphous TTCP. The vast majority of the available publications on ACPs in fact describe wet-precipitated compounds with $\mathrm{Ca} / \mathrm{P}$ ratio close to $~ 1.5$, i.e. amorphous TCP. As Poster's cluster has a chemical composition of TCP, it might be located in the atomic structures of HA (Fig. 12), TCPs and OCP. Since TTCP and all acidic calcium orthophosphates have the $\mathrm{Ca} / \mathrm{P}$ ionic ratios far away from 1.5 , presumably, at SRO and MRO scales, all of them in an amorphous state should contain structural units, which will be quite different from Posner's clusters. Nothing on this point has been found in the available literature. Obviously, this topic needs to be investigates in future.

In aqueous solutions, all currently known ACPs are easily converted into crystalline phases of calcium orthophosphates, especially into poorly crystalline CDHA. Therefore, advantages can be taken of ACPs' high reactivity to prepare various bioactive biomaterials. Currently, ACPs are involved as transient or constitutive phases in several commercial substitute bone materials, such as plasma sprayed coatings on metal prostheses and injectable cements for orthopedic applications. ACPs are also used for dental applications as fillers in ionomer cements to fill cavities or as colloidal suspensions in toothpastes, chewing gums or mouthwashes to promote remineralization of carious lesions and/or to prevent tooth demineralization[31]. Obviously, these examples are just the initial steps of the biomedical applications of ACPs.

As written above, the atomic structure of amorphous compounds is difficult to investigate due to the lack of LRO. Thus, in some of the aforementioned studies on ACPs, an "amorphous" character of the phases might be due to formation of nanodimensional and/or nanocrystalline calcium orthophosphates[340,341] with crystal dimensions of $2 \mathrm{~nm} \times$ $2 \mathrm{~nm} \times 2 \mathrm{~nm}\left(8 \mathrm{~nm}^{3}\right)$ or so (see section 2. Basic definitions and knowledge on the amorphous state of solids). Namely, employment of novel high resolution techniques resulted in doubt of the existence of several calcium orthophosphate samples in an amorphous state[342,343]. Therefore, there is still an unanswered question concerning the structure of the substantial amounts of nanodimensional and/or nanocrystalline calcium orthophosphates: whether they appear to be almost amorphous (according to numerous results of X-ray diffraction studies) due to their exceedingly small dimensions of well-crystallized structures or due to a really amorphous (i.e., retaining only a SRO) matter? A good attempt to discuss this topic is available in literature[344], where the interested readers are referred to.

To conclude, the biomedical applications of ACPs nowadays are limited due to great difficulties in their consolidations to various 3D structures, which have to possess the sufficient mechanical properties. As ACPs do not sustain heating at temperatures exceeding $\sim 600^{\circ} \mathrm{C}$, they must be consolidated by low temperature techniques only. Spark plasma sintering approach is one of them[31,289]. Another one comprises mixing of thermally unstable calcium orthophosphates with water soluble porogens, followed by cold isostatic pressing of the prepared mixture and dissolving the porogens[345]. Obviously, still other "mild" consolidation approaches are possible, those need to be developed. For example, a very interesting approach to fabricate hollow ACP-based nano-sized tubes has been proposed recently. These nano-sized tubes appear to be non-toxic to fibroblasts and can be taken up easily by mammalian cells[346]. Presumably, they may serve as vehicles for drugs and growth factors, as well as for tissue repair including bone regeneration.

\section{REFERENCES}

[1] Lowenstam, H.A., Weiner, S. On biomineralization. Oxford University Press, New York, USA. 1989, 324 pp.

[2] Gower, L.B. Biomimetic model systems for investigating the amorphous precursor pathway and its role in biomineralization. Chem. Rev. 2008, 108, 4551-4627.

[3] Lowenstam, H.A., Weiner, S. Transformation of amorphous calcium phosphate to crystalline dahillite in the radular teeth of chitons. Science 1985, 227, 51-53.

[4] Stricker, S.A., Weiner, S. Amorphous calcium phosphate in the stylets produced by a marine worm (Nemertea). Experientia 1985, 41, 1557-1559.

[5] Mitchell, P.C.H., Parker, S.F., Simkiss, K., Simmons, J., Taylor, M.G. Hydrated sites in biogenic amorphous calcium 
phosphates: an infrared, Raman, and inelastic neutron scattering study. J. Inorg. Biochem. 1996, 62, 183-197.

[6] Becker, A., Ziegler, A., Epple, M. The mineral phase in the cuticles of two species of Crustacea consists of magnesium calcite, amorphous calcium carbonate, and amorphous calcium phosphate. Dalton Transactions 2005, 10, 1814-1820.

[7] McGann, T.C.A., Buchheim, W., Kearney, R.D., Richardson, T. Composition and ultrastructure of calcium phosphate-citrate complexes in bovine milk systems. Biochim. Biophys. Acta 1983, 760, 415-420.

[8] McGann, T.C.A., Kearney, R.D., Buckheim, W. Amorphous calcium phosphate in casein micelles of bovine milk. Calcif. Tiss. Int. 1983, 35, 821-823.

[9] Brès, E.F., Moebus, G., Kleebe, H.J., Pourroy, G., Werkmann, J., Ehret, G. High resolution electron microscopy study of amorphous calcium phosphate. J. Cryst. Growth 1993, 129, 149-162.

[10] Raeymaekers, L., Agostini, B., Hasselbach, W. The formation of intravesicular calcium phosphate deposits in microsomes of smooth muscle: a comparison with sarcoplasmic reticulum of skeletal muscle. Histochemistry 1981, 70, 139-150.

[11] Termine, J.D., Posner, A.S. Infrared analysis of rat bone: age dependency of amorphous and crystalline mineral fractions. Science 1966, 153, 1523-1525.

[12] Termine, J.D., Wuthier, R.E., Posner, A.S. Amorphous-crystalline mineral changes during endochondral and periosteal bone formation. Proceedings of the Society for Experimental Biology and Medicine 1967, 125, 4-9.

[13] Eanes, E.D., Termine, J.D., Posner, A.S. Amorphous calcium phosphate in skeletal tissues. Clin. Orthop. Relat. Res. 1967, 53, 223-235.

[14] Tannenbaum, P.J., Schraer, H., Posner, A.S. Crystalline changes in avian bone related to the reproductive cycle. II. Percent crystallinity changes. Calcif. Tiss. Int. 1974, 14, 83-86.

[15] Glimcher, M.J., Bonar, L.C., Grynpas, M.D., Landis, W.J., Roufosse, A.H. Recent studies of bone mineral: is the amorphous calcium phosphate theory valid? J. Cryst. Growth 1981, 53, 100-119.

[16] Grynpas, M.D., Bonar, L.C., Glimcher, M.J. On the question of amorphous tricalcium phosphate in bone mineral. Dev. Biochem. 1981, 22, 279-283.

[17] Grynpas, M.D., Bonar, L.C., Glimcher, M.J. Failure to detect an amorphous calcium-phosphate solid phase in bone mineral: a radial distribution function study. Calcif. Tiss. Int. 1984, 36, 291-301.

[18] Aoba, T., Moreno. E. Changes in the nature and composition of enamel mineral during porcine amelogenesis. Calcif. Tiss. Int. 1990, 47, 356-364.

[19] Boskey, A.L. Amorphous calcium phosphate: the contention of bone. J. Dent. Res. 1997, 76, 1433-1436.

[20] Eanes, E.D. Amorphous calcium phosphate. In: Chow, L.C., Eanes, E.D. (Eds): Octacalcium phosphate. Monographs Oral Sci. Vol. 18. Karger, Basel, Switzerland. 2001, pp. 130-147.

[21] Weiner, S., Sagi. I., Addadi, L. Choosing the crystallization path less travelled. Science 2005, 309, 1027-1028.
[22] Weiner, S. Transient precursor strategy in mineral formation of bone. Bone 2006, 39, 431-433.

[23] Suvorova, E.I., Petrenko, P.P., Buffat, P.A. Scanning and transmission electron microscopy for evaluation of order/disorder in bone structure. Scanning 2007, 29, 162-170.

[24] Rey, C., Combes. C., Drouet, C., Glimcher. M.J. Bone mineral: an update on chemical composition and structure. Osteoporos. Int. 2009, 20, 1013-1321.

[25] Olszta, M.J., Odom, D.J., Douglas, E.P., Gower, L.B. A new paradigm for biomineral formation: mineralization via an amorphous liquid phase precursor. Connect. Tiss. Res. 2003, 44, 326-334.

[26] Mahamid, J., Sharir. A., Addadi, L., Weiner. S. Amorphous calcium phosphate is a major component of the forming fin bones of zebrafish: indications for an amorphous precursor phase. Proc. Natl. Acad. Sci. USA 2008, 105, 12748-12753.

[27] Mahamid, J., Aichmayer, B., Shimoni, E., Ziblat, R., Li, C., Siegel, S., Paris, O., Fratzl, P., Weiner, S., Addadi, L. Mapping amorphous calcium phosphate transformation into crystalline mineral from the cell to the bone in zebrafish fin rays. Proc. Natl. Acad. Sci. USA 2010, 107, 6316-6321.

[28] Tsuji, T., Onuma, K., Yamamoto, A., Iijima, M., Shiba, K. Direct transformation from amorphous to crystalline calcium phosphate facilitated by motif-programmed artificial proteins. Proc. Natl. Acad. Sci. USA 2008, 105, 16866-16870.

[29] Beniash, A., Metzler, R.A., Lam, R.S.K., Gilbert, P.U.P.A. Transient amorphous calcium phosphate in forming enamel. J. Struct. Biol. 2009, 166, 133-143.

[30] Tao, J., Pan, H., Zeng, Y., Xu, R., Tang, R. Roles of amorphous calcium phosphate and biological additives in the assembly of hydroxyapatite nanoparticles. J. Phys. Chem. B 2007, 111, 13410-13418.

[31] Combes, C., Rey, C. Amorphous calcium phosphates: synthesis, properties and uses in biomaterials. Acta Biomater. 2010, 6, 3362-3378.

[32] Dorozhkin, S.V. Calcium orthophosphates. J. Mater. Sci. 2007, 42, 1061-1095.

[33] Dorozhkin, S.V. Calcium orthophosphates in nature, biology and medicine. Materials 2009, 2, 399-498.

[34] Holt, C., van Kemenade, M.J.J.M., Harries, J.E., Nelson, L.S. Jr., Bailey, R.T., Hukins, D.W.L., Hasnain, S.S., de Bruyn, P.L. Preparation of amorphous calcium-magnesium phosphates at $\mathrm{pH} 7$ and characterization by X-ray absorption and Fourier transform infrared spectroscopy. J. Cryst. Growth 1988, 92, 239-252.

[35] Bachra, B.N. Precipitation of calcium carbonates and phosphates from metastable solutions. Ann. NY Acad. Sci. 1963, 109, 251-255.

[36] Bachra, B.N., Trautz, O.R., Simon, S.L. Precipitation of calcium carbonates and phosphates under physiological conditions. Arch. Biochem. Biophys. 1963, 103, 124-138.

[37] Bachra, B.N., Trautz, O.R., Simon, S.L. Precipitation of calcium carbonates and phosphates. III. The effect of magnesium and fluoride ions on the spontaneous precipitation of calcium carbonates and phosphates. Arch. Oral Biol. 1965, 10, 731-738. 
[38] Greenfield, D.J., Eanes, E.D. Formation chemistry of amorphous calcium phosphates prepared from carbonate containing solutions. Calcif. Tiss. Res. 1972, 9, 152-162.

[39] Olesen, P.T., Steenberg, T., Christensen. E., Bjerrum, N.J. Electrolytic deposition of amorphous and crystalline zinc-calcium phosphates. J. Mater. Sci. 1998, 33, 3059-3063.

[40] Tadic, D., Peters. F., Epple, M. Continuous synthesis of amorphous carbonated apatite. Biomaterials 2002, 23, 2553-2559.

[41] LeGeros. R.Z., Mijares, D., Park, J., Chang, X.F., Khairoun, I., Kijkowska, R., Dias, R., LeGeros, J.P. Amorphous calcium phosphates (ACP): formation and stability. Key Eng. Mater. 2005, 284-286, 7-10.

[42] Aimanova, O.J., LeGeros, R.Z., Sinyayev, V.A. Antimicrobiologic property hydrated amorphous calcium phosphates containing silver. Key Eng. Mater. 2005, 284-286, 439-442.

[43] Skrtic, D., Antonucci, J.M., Eanes, E.D., Brunworth, R.T. Silica- and zirconia-hybridized amorphous calcium phosphate: effect on transformation to hydroxyapatite. J. Biomed. Mater. Res. 2002, 59, 597-604.

[44] Julien, M., Khairoun, I., LeGeros, R.Z., Delplace, S., Pilet, P., Weiss, P., Daculsi, G., Bouler, J.M., Guicheux, J. Physico-chemical-mechanical and in vitro biological properties of calcium phosphate cements with doped amorphous calcium phosphates. Biomaterials 2007, 28, 956-965.

[45] Sinyaev, V.A., LeGeros, R.Z., Levchenko, L.V., Shustikova, E.S., Karzhaubaeva, R.A. State of water in amorphous calcium and calcium-magnesium phosphates. Russ. J. General Chem. 2008, 78, 864-867.

[46] Sinyaev, V.A., Shustikova, E.S., Levchenko, L.V., Karzhaubaeva, R.A., Tokseitova, G.A. Amorphous calcium barium monophosphate and its dehydration in air at room temperature. Russ. J. Appl. Chem. 2008, 81, 1899-1903.

[47] Lee, D., Kumta, P.N. Chemical synthesis and characterization of magnesium substituted amorphous calcium phosphate (MG-ACP). Mater. Sci. Eng. C 2010, 30, 1313-1317.

[48] Taylor, M.G., Simkiss, K., Simmons, J., Wu, L.N.Y., Wuthier, R.E. Structural studies of a phosphatidyl serine-amorphous calcium phosphate complex. Cell. Mol. Life Sci. 1998, 54, 196-202.

[49] Brečević, L., Hlady, V., Füredi-Milhofer, H. Influence of gelatin on the precipitation of amorphous calcium phosphate. Colloids Surf. 1987, 28, 301-313.

[50] Ambrosio, A.M.A., Sahota, J.S., Khan, Y., Laurencin C.T. A novel amorphous calcium phosphate polymer ceramic for bone repair: I. Synthesis and characterization. J. Biomed. Mater. Res. 2001, 58, 295-301.

[51] Skrtic, D., Antonucci, J.M., Eanes, E.D., Eichmiller, F.C., Schumacher, G.E. Physicochemical evaluation of bioactive polymeric composites based on hybrid amorphous calcium phosphates. J. Biomed. Mater. Res. (Appl. Biomater.) 2000, 53, 381-391.

[52] Skrtic, D., Antonucci, J.M., Eanes, E.D. Effect of the monomer and filler system on the remineralizing potential of bioactive dental composites based on amorphous calcium phosphate. Polym. Adv. Technol. 2001, 12, 369-379.
[53] Skrtic, D., Antonucci, J.M., Eanes, E.D. Amorphous calcium phosphate-based bioactive polymeric composites for mineralized tissue regeneration. J. Res. Natl. Inst. Stands. Technol. 2003, 108, 167-182.

[54] Skrtic, D., Antonucci, J.M., Eanes, E.D., Eidelman, N. Dental composites based on hybrid and surface-modified amorphous calcium phosphates. Biomaterials 2004, 25, 1141-1150.

[55] Skrtic, D., Antonucci, J.M. Matrix resin effects on selected physicochemical properties of amorphous calcium phosphate composites. J. Bioactive Compatible Polym. 2005, 20, 29-49.

[56] Skrtic, D., Antonucci, J.M., Eanes, E.D. Improved properties of amorphous calcium phosphate fillers in remineralizing resin composites. Dent. Mater. 1996, 12, 295-301.

[57] Skrtic, D., Antonucci, J.M. Dental composites based on amorphous calcium phosphate - resin composition/physicochemical properties study. J. Biomater. Applic. 2007, 21, 375-393.

[58] Skrtic, D., Antonucci, J.M., Liu, D.W. Ethoxylated bisphenol dimethacrylate-based amorphous calcium phosphate composites. Acta Biomater. 2006, 2, 85-94.

[59] Skrtic, D., Hailer A.W., Takagi, S., Antonucci, J.M., Eanes, E.D. Quantitative assessment of the efficacy of amorphous calcium phosphate/methacrylate composites in remineralizing caries-like lesions artificially produced in bovine enamel. J. Dental Res. 1996, 75, 1679-1686.

[60] Park, M.S., Eanes, E.D., Antonucci, J.M., Skrtic, D. Mechanical properties of bioactive amorphous calcium phosphate/methacrylate composites. Dent. Mater. 1998, 14, 137-141.

[61] Lee, S.Y., Regnault, W.F., Antonucci, J.M., Skrtic, D. Effect of particle size of an amorphous calcium phosphate filler on the mechanical strength and ion release of polymeric composites. J. Biomed. Mater. Res. B (Appl. Biomater.) 2007, 80B, 11-17.

[62] Antonucci, J.M., Liu, D.W., Skrtic, D. Amorphous calcium phosphate based composites: effect of surfactants and poly(ethylene oxide) on filler and composite properties. J. Dispersion Sci. Technol. 2007, 28, 819-824.

[63] Skrtic, D., Lee, S.Y., Antonucci, J.M., Liu, D.W. Amorphous calcium phosphate based polymeric composites: effects of polymer composition and filler's particle size on composite properties. Key Eng. Mater. 2005, 284-286, 737-740.

[64] O’Donnell, J.N.R., Schumacher, G.E., Antonucci, J.M., Skrtic, D. Adhesion of amorphous calcium phosphate composites bonded to dentin: a study in failure modality. J. Biomed. Mater. Res. B (Appl. Biomater.) 2009, 90B, 238-249.

[65] Antonucci, J.M., O’Donnell, J.N.R., Schumacher, G.E., Skrtic, D. Amorphous calcium phosphate composites and their effect on composite-adhesive-dentin bonding. J. Adhes. Sci. Technol. 2009, 23, 1133-1147.

[66] Reynolds, E.C., Cai, F., Cochrane, N.J., Shen, P., Walker, G.D., Morgan, M.V., Reynolds, C. Fluoride and casein phosphopeptide-amorphous calcium phosphate. J. Dent. Res. 2008, 87, 344-348.

[67] Amjad, Z. Influence of polyelectrolytes on the precipitation of amorphous calcium phosphate. Colloids Surf. 1990, 48, 
95-106.

[68] Bar-Yosef, O.P., Govrin-Lippman, R., Garti, N., Füredi-Milhofer, H. The influence of polyelectrolytes on the formation and phase transformation of amorphous calcium phosphate. Cryst. Growth Des. 2004, 4, 177-183.

[69] Cross, K.J., Huq, N.L., Palamara, J.E., Perich, J.W., Reynolds, E.C. Physicochemical characterisation of casein phosphopeptide-amorphous calcium phosphate nanocomplexes. J. Biological Chem. 2005, 280, 15362-15369.

[70] Gutiérrez, M.C., Jobbágy, M., Ferrer, M.L., del Monte, F. Enzymatic synthesis of amorphous calcium phosphate-chitosan nanocomposites and their processing into hierarchical structures. Chem. Mater. 2008, 20, 11-13.

[71] Cushnie, E.K., Khan, Y.M., Laurencin, C.T. Amorphous hydroxyapatite-sintered polymeric scaffolds for bone tissue regeneration: physical characterization studies. J. Biomed. Mater. Res. A 2008, 84A, 54-62.

[72] Ikawa, N., Kimura, T., Oumi, Y., Sano, T. Amino acid containing amorphous calcium phosphates and the rapid transformation into apatite. J. Mater. Chem. 2009, 19, 4906-4913.

[73] Lin, Q., Li, Y., Lan, X., Lu, C., Xu, Z. Preparation of amorphous calcium phosphate/tricalcium silicate composite powders. Adv. Mater. Res. 2009, 79-82, 1643-1646.

[74] Walker, G.D., Cai, F., Shen, P., Adams, G.G., Reynolds, C., Reynolds, E.C. Casein phosphopeptide-amorphous calcium phosphate incorporated into sugar confections inhibits the progression of enamel subsurface lesions in situ. Caries Res. 2010, 44, 33-40.

[75] Antonucci, J.M., Regnault, W.F., Skrtic, D. Polymerization shrinkage and stress development in amorphous calcium phosphate / urethane dimethacrylate polymeric composites. J. Composite Mater. 2010, 44, 355-367.

[76] Sinyaev, V.A., Shustikova, E.S., Levchenko, L.V., Sedunov, A.A. Synthesis and dehydration of amorphous calcium phosphate. Inorg. Mater. 2001, 37, 619-622.

[77] Dion, A., Berno, B., Hall, G., Filiaggi, M.J. The effect of processing on the structural characteristics of vancomycin-loaded amorphous calcium phosphate matrices. Biomaterials 2005, 26, 4486-4494.

[78] Dion, A., Langman, M., Hall, G., Filiaggi, M.J. Vancomycin release behaviour from amorphous calcium polyphosphate matrices intended for osteomyelitis treatment. Biomaterials 2005, 26, 7276-7285.

[79] Lee, B., Kim, M., Choi, S., Lee, Y.K. Amorphous calcium polyphosphate bone regenerative materials based on calcium phosphate glass. Key Eng. Mater. 2009, 396-398, 209-212.

[80] Chen, G., Li, W., Zhao, B., Sun, K. A novel biphasic bone scaffold: $\beta$-calcium phosphate and amorphous calcium polyphosphate. J. Am. Ceram. Soc. 2009, 92, 945-948.

[81] Chun, S., Jeong, J.H., Kim, K.M., Kim, S. Biodegradation study of amorphous and crystalline calcium metaphosphate in the SBF and tris-buffer solution. Key Eng. Mater. 2001, 192-195, 131-134.

[82] Cheng, Y.T., Johnson, W.L. Disordered materials: a survey of amorphous solids. Science 1987, 235, 997-1002.
[83] http://en.wikipedia.org/wiki/Amorphous (accessed in October 2011).

[84] Sheng, H.W., Luo, W.K., Alamgir, F.M., Bai, J.M., Ma, E. Atomic packing and short-to-medium-range order in metallic glasses. Nature 2006, 439, 419-425.

[85] Lee, C.Y., Stachurski, Z.H., Welberry, T.R. The geometry, topology and structure of amorphous solids. Acta Mater. 2010, 58, 615-625.

[86] Hufnagel, T.C. Amorphous materials: finding order in disorder. Nature Mater. 2004, 3, 666-667.

[87] Elliott, S.R. Physics of amorphous materials. 2nd Ed. Longman, London, UK. 1990, 481 pp.

[88] Elliott, S.R. Medium-range structural order in covalent amorphous solids. Nature 1991, 354, 445-452.

[89] Salmon, P.S. Amorphous materials: order in disorder. Nature Mater. 2002, 1, 87-88.

[90] Krivanek, O.L., Gaskell, P.H., Howie, A. Seeking order in 'amorphous' materials. Nature 1976, 362, 454-457.

[91] Mountjoy, G. Order in two-dimensional projections of thin amorphous three-dimensional structures. J. Phys. Cond. Matter 1999, 11, 2319-2336.

[92] Simon, V., Lazăr, D., Turcu, R.V.F., Mocuta, H., Magyari. K., Prinz, M., Neumann, M., Simon, S. Atomic environment in sol-gel derived nanocrystalline hydroxyapatite. Mater. Sci. Eng. B 2009, 165, 247-251.

[93] Weeber, A.W., Bakker, H. Amorphization by ball milling. A review. Physica B 1988, 153, 93-135.

[94] Maier, G., Zipper, P., Stubičar, M., Schurz, J. Amorphization of different cellulose samples by ball milling. Cellulose Chem. Technol. 2005, 39, 167-177.

[95] Motta, A.T. Amorphization of intermetallic compounds under irradiation - a review. J. Nucl. Mater. 1997, 244, 227-250.

[96] Edmondson, P.D., Riley, D.J., Birtcher, R.C., Donnelly, S.E. Amorphization of crystalline Si due to heavy and light ion irradiation. J. Appl. Phys. 2009, 106, 043505 (8 pages).

[97] Robinson, R.A., Watson, M.L. Crystal-collagen relationships in bone as observed in the electron microscope. III. Crystal and collagen morphology as a function of age. Ann. NY Acad. Sci. 1955, 60, 596-660.

[98] Watson, M.L., Robinson, R.A. Collagen-crystal relationships in bone. II. Electron microscope study of basic calcium phosphate crystals. Am. J. Anat. 1953, 93, 25-59.

[99] Chow, L.C., Takagi, S., Vogel, G.L. Letter to the Editor. J. Dent. Res. 1998, 77, 6.

[100] Eanes, E.D. Letter to the Editor. J. Dent. Res. 1998, 77, 6.

[101] Harper, R,A., Posner, A.S. Measurement of non-crystalline calcium phosphate in bone mineral. Proc. Soc. Exp. Biol. Med. 1966, 122, 137-142.

[102] Termine, J.D., Posner, A.S. Amorphous/crystalline interrelationships in bone mineral. Calcif. Tiss. Res. 1967, 1, 8-23.

[103] Posner, A.S. Crystal chemistry of bone mineral. Physiol. Rev. 1969, 40, 760-792. 
[104] Posner, A.S., Betts, F. Synthetic amorphous calcium phosphate and its relation to bone mineral structure. Acc. Chem. Res. 1975, 8, 273-281.

[105] Betts, F., Blumenthal, N.C., Posner, A.S., Becker, G.L., Lehninger, A.L. Atomic structure of intracellular amorphous calcium phosphate deposits. Proc. Nat. Acad. Sci. USA 1975, 72, 2088-2090.

[106] Posner, A.S., Betts, F., Blumenthal, N.C. Formation and structure of synthetic and bone hydroxyapatite. Progr. Cryst. Growth Char. 1980, 3, 49-64.

[107] Bonar, L.C., Roufousse, A.H., Sabine, W.K., Grynpass, M.D., Glimcher, M.J. X-ray diffraction studies of the crystallinity of bone mineral in newly synthesized and density fractionated bone. Calcif. Tiss. Int. 1983, 35, 202-209.

[108] Molnar, Z. Development of the parietal bone of young mice I. Crystals of bone mineral in frozen-dried preparations. J. Ultrastruct. Res. 1959, 3, 39-45.

[109] Molnar, Z. Additional observations on bone crystal dimensions. Clin. Orthop. 1960, 17, 38-42.

[110] Thyberg, J. Electron microscopic studies on the initial phases of calcification in guinea pig epiphyseal cartilage. J. Ultrastruct. Res. 1974, 46, 206-218.

[111] Gay, C.V. The ultrastructure of the extracellular phase of bone as observed in frozen thin sections. Calcif. Tiss. Res. 1977, 23, 215-223.

[112] Schraer, H., Gay, C.V. Matrix vesicles in newly synthesizing bone observed after ultracryotomy and ultramicroincineration. Calcif. Tiss. Res. 1977, 23, 185-188.

[113] Nancollas, G.H., Mohan, M.S. The growth of hydroxyapatite crystals. Arch. Oral Biol. 1970, 15, 731-745.

[114] Blumenthal, N.C., Betts, F., Posner, A.S. Formation and structure of Ca-deficient hydroxyapatite. Calcif. Tiss. Int. 1981, 33, 111-117.

[115] Meyer, J.L. Phase transformations in the spontaneous precipitation of calcium phosphate. Croatica Chim. Acta 1983, 56, 753-767.

[116] Harries, J.E., Hukins, D.W.L., Holt, C., Hasnain. S.S. Conversion of amorphous calcium phosphate into hydroxyapatite investigated by EXAFS spectroscopy. J. Cryst. Growth 1987, 84, 563-570.

[117] Lopez-Valero, I., Gomez-Lorente, C., Boistelle, R. Effects of sodium and ammonium ions on occurrence., evolution and crystallinity of calcium phosphates. J. Cryst. Growth 1992, 121, 297-304.

[118] Lazić, S. Microcrystalline hydroxyapatite formation from alkaline solutions. J. Cryst. Growth 1995, 147, 147-154.

[119] Gadaleta, S.J., Paschalis, E.P., Betts, F., Mendelson, R., Boskey, A.L. Fourier transform infrared spectroscopy of the solution-mediated conversion of amorphous calcium phosphate to hydroxyapatite: new correlations between X-ray diffraction and infrared data. Calcif. Tiss. Int. 1996, 58, 9-16.

[120] Tarasevich, B.J., Chusuei, C.C., Allara, D.L. Nucleation and growth of calcium phosphate from physiological solutions onto self-assembled templates by a solution-formed nucleus mechanism. J. Phys. Chem. B 2003, 107, 10367-10377.
[121] Kim, S., Ryu, H.S., Jung, H.S., Hong, K.S. Influence of Ca/P ratios of starting solutions on the crystallization of amorphous calcium phosphate to hydroxyapatite. Metals Mater. Int. 2004, $10,171-175$.

[122] Kim, S., Ryu, H.S., Shin, H., Jung, H.S., Hong, K.S. Direct observation of hydroxyapatite nucleation from amorphous phase in a stoichiometric calcium/phosphate aqueous solution. Chem. Lett. 2004, 33, 1292-1293.

[123] Wang, L., Nancollas, G.H. Calcium orthophosphates: crystallization and dissolution. Chem. Rev. 2008, 108, 4628-4669.

[124] Brečević, LJ., Füredi-Milhofer, H. Precipitation of calcium phosphates from electrolyte solutions - II. The formation and transformation of the precipitates. Calcif. Tiss. Res. 1972, 10, 82-90.

[125] Liu, C., Huang, Y., Shen, W., Cui, J. Kinetics of hydroxyapatite precipitation at $\mathrm{pH} 10$ to 11 . Biomaterials 2001, 22, 301-306.

[126] Boskey, A.L., Posner, A.S. Formation of hydroxyapatite at low supersaturation. J. Phys. Chem. 1976, 80, 40-45.

[127] Feenstra, T.P., de Bruyn, P.L. The Ostwald rule of stages in precipitation from highly supersaturated solutions: a model and its application to the formation of the nonstoichiometric amorphous calcium phosphate precursor phase. J. Coll. Interf. Sci. 1981, 84, 66-72.

[128] Eanes, E.D. Amorphous calcium phosphate: thermodynamic and kinetic considerations. In: Amjad, Z. (Ed): Calcium phosphates in biological and industrial systems. Kluwer. MA, USA, 1998, pp. 21-39.

[129] Blumenthal, N.C., Posner, A.S., Holmes, J.M. Effect of preparation conditions on the properties and transformation of amorphous calcium phosphate. Mater. Res. Bull. 1972, 7, 1181-1189.

[130] Boskey, A.L., Posner, A.S. Conversion of amorphous calcium phosphate to microcrystalline hydroxyapatite. A pH-dependent., solution-mediated., solid-solid conversion. J. Phys. Chem. 1973, 77, 2313-2317.

[131] Li, Y., Weng, W. In vitro synthesis and characterization of amorphous calcium phosphates with various $\mathrm{Ca} / \mathrm{P}$ atomic ratios. J. Mater. Sci. Mater. Med. 2007, 18, 2303-2308.

[132] Zyman, Z.Z., Rokhmistrov, D.V., Glushko, V.I. Structural and compositional features of amorphous calcium phosphate at the early stage of precipitation. J. Mater. Sci. Mater. Med. 2010, 21, 123-130.

[133] Holt, C., van Kemenade, M.J.J.M., Nelson, L.S. Jr., Hukins, D.W.L., Bailey, R.T., Harries, J.E., Hasnain, S.S., de Bruyn, P.L. Amorphous calcium phosphates prepared at $\mathrm{pH} 6.5$ and 6.0. Mater. Res. Bull. 1989, 23, 55-62.

[134] Eanes, E.D., Gillessen, I.H., Posner, A.S. Intermediate states in the precipitation of hydroxyapatite. Nature 1965, 208, 365-367.

[135] Urch, H., Vallet-Regi, M., Ruiz, L., Gonzalez-Calbet, J.M., Epple M. Calcium phosphate nanoparticles with adjustable dispersability and crystallinity. J. Mater. Chem. 2009, 19, 2166-2171.

[136] Kim, S., Ryu, H.S., Shin, H., Jung, H.S., Hong, K.S. In situ 
observation of hydroxyapatite nanocrystal formation from amorphous calcium phosphate in calcium-rich solutions. Mater. Chem. Phys. 2005, 91, 500-506.

[137] Termine, J.D., Eanes, E.D. Comparative chemistry of amorphous and apatitic calcium phosphate preparations. Calcif. Tiss. Res 1972, 10, 171-197.

[138] Zahidi, E., Lebugle, A., Bonel, G. Sur une nouvelle classe de materiaux pour protheses osseuses ou dentaires. [A new class of materials for bone or dental prostheses]. Bull. Sot. Chim. Fr. 1985, 4, 523-527.

[139] Lebugle, A., Zahidi, E., Bonel, G. Effect of structure and composition on the thermal decomposition of calcium phosphates $(\mathrm{Ca} / \mathrm{P}=1.33)$. React Solids 1986, 2, 151-161.

[140] Layrolle, P., Lebugle, A. Characterization and reactivity of nanosized calcium phosphates prepared in anhydrous ethanol. Chem. Mater. 1994, 6, 1996-2004.

[141] Layrolle, P., Ito, A., Tateishi, T. Sol-gel synthesis of amorphous calcium phosphate and sintering into microporous hydroxyapatite bioceramics. J. Am. Ceram. Soc. 1998, 81, 1421-1428.

[142] Rodrigues, A., Lebugle, A. Behavior in wet atmosphere of an amorphous calcium phosphate with an atomic $\mathrm{Ca} / \mathrm{P}$ ratio of 1.33. J. Solid State Chem. 1999, 148, 308-315.

[143] Ohta, M., Honma, T., Umesaki, M., Nakahira, A. Synthesis and evaluation of amorphous calcium phosphate (ACP) by various synthesis methods. Key Eng. Mater. 2006, 309-311, $175-178$.

[144] Li, Y.B., Weng, W.J., Cheng, K., Du. P.Y., Shen, G., Han, G.R. Complexes of $\mathrm{Ca}(\mathrm{II})$ with polymers as precursors for preparation of amorphous calcium phosphate. Mater. Sci. Technol. 2004, 20, 1075-1078.

[145] Bow, J.S., Liou, S.C., Chen, S.Y. Structural characterization of room-temperature synthesized nano-sized $\beta$-tricalcium phosphate. Biomaterials 2004, 25, 3155-3161.

[146] Li, Y.B., Weng, W.J., Cheng, K., Du, P.Y., Shen, G., Wang J., Han G.R. Preparation of amorphous calcium phosphate in the presence of poly(ethylene glycol). J. Mater. Sci. Lett. 2003, 22, 1015-1016.

[147] Wang, R., Weng, W., Deng, X., Cheng, K., Liu, X., Du, P., Shen, G., Han, G. Dissolution behavior of submicron biphasic tricalcium phosphate powders. Key Eng. Mater. 2006, 309-311, 223-226.

[148] Li, Y., Wiliana, T., Tam, K.C. Synthesis of amorphous calcium phosphate using various types of cyclodextrins. Mater. Res. Bull. 2007, 42, 820-827.

[149] Tao, J., Pan, H., Zhai, H., Wang, J., Li, L., Wu, J., Jiang, W., $\mathrm{Xu}, \mathrm{X}$., Tang, R. Controls of tricalcium phosphate single-crystal formation from its amorphous precursor by interfacial energy. Cryst. Growth Des. 2009, 9, 3154-3160.

[150] Liu, S., Weng, W., Li, Z., Pan, L., Cheng, K., Song, C., Du, P., Shen, G., Han, G. Effect of PEG amount in amorphous calcium phosphate on its crystallized products. J. Mater. Sci. Mater. Med. 2009, 20, 359-363.

[151] Li, Y., Weng, W., Tam, K.C. Novel highly biodegradable biphasic tricalcium phosphates composed of $\alpha$-tricalcium phosphate and $\beta$-tricalcium phosphate. Acta Biomater. 2007,

\section{3, 251-254}

[152] Li, Y., Li, D., Weng, W. In vitro dissolution behavior of biphasic tricalcium phosphate composite powders composed of $\alpha$-tricalcium phosphate and $\beta$-tricalcium phosphate. Key Eng. Mater. 2008, 368-372, 1206-1208.

[153] Rodrigues, A., Lebugle, A. Influence of ethanol in the precipitation medium on the composition., structure and reactivity of tricalcium phosphate. Colloids Surf. A 1998, 145, 191-204.

[154] Heughebaert, J.C., Montel, G. Conversion of amorphous tricalcium phosphate into apatitic tricalcium phosphate. Calcif. Tiss. Int. 1982, 34, S103-S108.

[155] Yu, T., Ye, J., Wang, Y. Synthesis and property of a novel calcium phosphate cement. J. Biomed. Mater. Res. B (Appl. Biomater.) 2009, 90B, 745-751.

[156] Tofighi, A., Palazzolo, R. Calcium phosphate bone cement preparation using mechano-chemical process. Key Eng. Mater. 2005, 284-286, 101-104.

[157] Gbureck, U., Grolms, O., Barralet, J.E., Grover, L.M., Thull, R. Mechanical activation and cement formation of $\beta$-tricalcium phosphate. Biomaterials 2003, 24, 4123-4131.

[158] Gbureck, U., Barralet, J.E., Radu, L., Klinger, H., Thull, R. Amorphous $\alpha$-tricalcium phosphate: preparation and aqueous setting reaction. J. Am. Ceram. Soc. 2004, 87, 1126-1132.

[159] Gbureck, U., Hofmann, M.P., Barralet, J.E. Thermal performance of mechanically activated tetracalcium phosphate. J. Am. Ceram. Soc. 2005, 88, 1327-1330.

[160] Vaidya, S.N., Karunakaran, C., Pande, B.M., Gupta, N.M., Iyer, R.K., Karweer, S.B. Pressure-induced crystalline to amorphous transition in hydroxylapatite. J. Mater. Sci. 1997, 32, 3213-3217.

[161] Vaidya, S.N., Sugandhi, V. Pressure induced amorphization in calcium phosphates. J. Mater. Sci. 1999, 34, 3769-3778.

[162] Lemons, J.E. Hydroxyapatite coatings. Clin. Orthop. 1988, 235, 220-223.

[163] Zyman, Z.Z., Weng, J., Liu, X., Zhang, X., Ma, Z. Amorphous phase and morphological structure of hydroxyapatite plasma coatings. Biomaterials 1993, 14, 225-228.

[164] Weng, J., Liu, X., Zhang, X., Ma, Z., Ji, X., Zyman, Z.Z. Further studies on the plasma-sprayed amorphous phase in hydroxyapatite coatings and its deamorphization. Biomaterials $1993,14,578-582$.

[165] Tong, W., Chen, J., Zhang, X. Amorphorization and recrystallization during plasma spraying of hydroxyapatite. Biomaterials 1995, 16, 829-832.

[166] Weng, J., Liu, X.G., Li, X.D., Zhang, X.D. Intrinsic factors of apatite influencing its amorphization during plasma-spray coating. Biomaterials 1995, 16, 39-44.

[167] Gross, K.A., Berndt, C.C., Herman, H. Amorphous phase formation in plasma-sprayed hydroxyapatite coatings. J. Biomed. Mater. Res. 1998, 39, 407-414.

[168] Feng, C.F., Khor, K.A., Kweh, S.W.K., Cheang, P. Thermally induced crystallization of amorphous calcium phosphate in plasma-spheroidized hydroxyapatite powders. Mater. Lett. 2000, 46, 229-233. 
[169] 1Tong, W., Li, P. In vitro dissolution of amorphous calcium phosphate (Acp) increased the wear particle generation of plasma-sprayed HA coatings. Key Eng. Mater. 2007, 330-332, 561-564.

[170] Gross, K.A., Phillips, M.R. Identification and mapping of the amorphous phase in plasma-sprayed hydroxyapatite coatings using scanning cathodoluminescence microscopy. J. Mater. Sci. Mater. Med. 1998, 9, 797-802.

[171] Carayon, M.T., Lacout, J.L. Study of the Ca/P atomic ratio of the amorphous phase in plasma-sprayed hydroxyapatite coatings. J. Solid State Chem. 2003, 172, 339-350.

[172] Kumar, R., Cheang, P., Khor, K.A. Phase composition and heat of crystallization of amorphous calcium phosphate in ultra-fine radio frequency suspension plasma sprayed hydroxyapatite powders. Acta Mater. 2004, 52, 1171-1181.

[173] Keller, L., Dollase, W.A. X-ray determination of crystalline hydroxyapatite to amorphous calcium-phosphate ratio in plasma sprayed coatings. J. Biomed. Mater. Res. 2000, 49, 244-249.

[174] Gross, K.A., Gross, V., Berndt, C.C. Thermal analysis of amorphous phases in hydroxyapatite coatings. J. Am. Ceram. Soc. $1998,81,106-112$.

[175] Döbelin, N., Brunner, T.J., Stark, W.J., Eggimann, M., Fisch, M., Bohner, M. Phase evolution of thermally treated amorphous tricalcium phosphate nanoparticles. Key Eng. Mater. 2009, 396-398, 595-598.

[176] Maciejewski, M., Brunner, T.J., Loher, S,F., Stark, W.J., Baiker, A. Phase transitions in amorphous calcium phosphates with different $\mathrm{Ca} / \mathrm{P}$ ratios. Thermochim. Acta 2008, $468,75-80$.

[177] Tisserand, R., Rebetez, M., Grivet, M., Bouffard, S., Benyagoub, A., Levesque, F., Carpena, J. Comparative amorphization quantification of two apatitic materials irradiated with heavy ions using XRD and RBS results. Nucl. Instrum. Methods Phys. Res. B 2004, 215, 129-136.

[178] Weikusat, C., Glasmacher, U.A., Schuster, B., Trautmann, C., Miletich, R., Neumann, R. Raman study of apatite amorphised with swift heavy ions under various irradiation conditions. Phys. Chem. Minerals 2011, 38, 293-303.

[179] Eanes, E.D., Posner, A.S. Intermediate phases in the basic solution preparation of alkaline earth phosphates. Calcif. Tiss. Res. 1968, 2, 38-48.

[180] Nylen, M.U., Eanes, E.D., Termine, J.D. Molecular and ultrastructural studies of noncrystalline calcium phosphates. Calcif. Tiss. Res. 1972, 9, 95-108.

[181] Eanes, E.D., Termine, J.D., Nylen, M.U. An electron microscopic study of the formation of amorphous calcium phosphate and its transformation to crystalline apatite. Calcif. Tiss. Res. 1973, 12, 143-158.

[182] Eanes, E.D. Amorphous intermediates in the formation of biological apatites. Physico-chimie et cristallographie des apatites d'intérêt biologique. Coll. Int. CNRS 1975, 230, 295-301.

[183] Barton, S.S., Harrison, B.H. Surface and bulk properties of amorphous calcium phosphate. In: Kerker, M. (Ed.): Colloid and Interface Science. Vol. 3. 50 ${ }^{\text {th }}$ Proceeding Int'l Conf. Academic Press, New York, USA. 1976. p. 71.
[184] Lundager-Madsen, H.E., Lopez-Valero, I., Lopez-Acevedo, $\mathrm{V}$. The formation product of amorphous tricalcium phosphate at $37^{\circ} \mathrm{C}$. J. Cryst. Growth 1986, 75, 429-434.

[185] Roberts, J.E., Heughebaert, M., Heughebaert. J.C., Bonar, L.C., Glimcher, M.J., Griffin, R.G. Solid state ${ }^{31}$ NMR studies of the conversion of amorphous tricalcium phosphate to apatitic tricalcium phosphate. Calcif. Tiss. Int. 1991, 49, 378-382.

[186] Gbureck, U., Barralet, J.E., Thull, R. Thermodynamic study of formation of amorphous $\beta$-tricalcium phosphate for calcium phosphate cements. Key Eng. Mater. 2004, 254-256, 249-252.

[187] Brunner, T.J., Bohner, M., Dora, C., Gerber, C., Stark, W.J. Comparison of amorphous TCP nanoparticles to micron-sized $\alpha$-TCP as starting materials for calcium phosphate cements. J. Biomed. Mater. Res. B (Appl. Biomater.) 2007, 83B, 400-407.

[188] Brunner, T.J., Grass, R.N., Bohner, M., Stark, W.J. Effect of particle size, crystal phase and crystallinity on the reactivity of tricalcium phosphate cements for bone reconstruction. J. Mater. Chem. 2007, 17, 4072-4078.

[189] Somrani, S., Rey, C., Jemal, M. Thermal evolution of amorphous tricalcium phosphate. J. Mater. Chem. 2003, 13, 888-892.

[190] Somrani, S., Banu, M., Jemal, M., Rey, C. Physico-chemical and thermochemical studies of the hydrolytic conversion of amorphous tricalcium phosphate into apatite. J. Solid State Chem. 2005, 178, 1337-1348.

[191] Mohn, D., Ege, D., Feldman, K., Schneider, O.D., Imfeld, T., Boccaccini, A.R., Stark, W.J. Spherical calcium phosphate nanoparticle fillers allow polymer processing of bone fixation devices with high bioactivity. Polym. Eng. Sci. 2010, 50, 952-960.

[192] Dekker, R.J., de Bruijn, J.D., Stigter, M., Barrere, F., Layrolle, P., van Blitterswijk, C.A. Bone tissue engineering on amorphous carbonated apatite and crystalline octacalcium phosphate-coated titanium discs. Biomaterials 2005, 26, 5231-5239.

[193] Amin, M.S., Randeniya, L.K., Bendavid, A., Martin, P.J., Preston, E.W. Amorphous carbonated apatite formation on diamond-like carbon containing titanium oxide. Diamond and Related Materials 2009, 18, 1139-1144.

[194] Imai, H., Kusunoki, M., Hashimoto, Y., Nishikawa, H., Hontsu, S. Evaluation of biological molecular adsorption on hydroxyapatite and amorphous $\mathrm{Ca}_{10}\left(\mathrm{PO}_{4}\right)_{6}(\mathrm{OH})_{2}$ thin films using QCM method. IEEJ Trans. EIS 2007, 127, 1839-1842.

[195] Holt, C., Wahlgren, N.M., Drakenberg, T. Ability of a $\beta$-casein phosphopeptide to modulate the precipitation of calcium phosphate by forming amorphous dicalcium phosphate nanoclusters. Biochem. J. 1996, 314, 1035-1039.

[196] Eanes, E.D., Posner, A.S. Kinetics and mechanism of conversion of noncrystalline calcium phosphate to crystalline hydroxyapatite. Trans. NY Acad. Sci. 1965, 28, 233-241.

[197] Eanes, E.D. Thermochemical studies on amorphous calcium phosphate. Calcif. Tiss. Res. 1970, 5, 133-145.

[198] Oniki, T., Oyamada, M. Surface structure of amorphous calcium phosphate by ESR of $\mathrm{VO}^{2+}$ adsorbed on it. Calcif. 
Tiss. Int. 1983, 35, 477-480.

[199] Boulet, M., Marier, J.R. Precipitation of calcium phosphates from solutions at near physiological concentrations. Arch. Biochem. 1961, 98, 157-165.

[200] Newesely, H. Changes in crystal types of low solubility calcium phosphates in the presence of accompanying ions. Arch. Oral Biol. 1961, Spec. Suppl. 6, 174-180.

[201] VuiIleumier, C., Lerch, P. Étude de la structure, par la diffraction des rayons $X$ et la microscopic é1ectronique, de l'hydroxylapatite calcique et des orthophosphates dits tri- et octacalcique. Helv. Chim. Acta 1966, 49, 663-670.

[202] Christoffersen, J., Christoffersen, M.R., Kibalczyc, W., Andersen, F.A. A contribution to the understanding of the formation of calcium phosphates. J. Cryst. Growth 1989, 94, 767-777.

[203] Christoffersen, J., Christoffersen, M.R., Kibalczyc, W. Apparent solubilities of two amorphous calcium phosphates and of octacalcium phosphate in the temperature range $30-42^{\circ} \mathrm{C}$. J. Cryst. Growth 1990, 106, 349-354.

[204] Kibalczyc, W., Christoffersen, J., Christoffersen, M.R., Zielenkiewicz, A., Zielenkiewicz, W. The effect of magnesium ions on the precipitation of calcium phosphates. J. Cryst. Growth 1990, 106, 355-366.

[205] Francis, M.D., Webb, N.C. Hydroxyapatite formation from a hydrated calcium monohydrogen phosphate precursor. Calcif. Tiss. Res. 1971, 6, 335-342.

[206] Walton, A.G., Bodin, W.J., Furedi, H., Sehwartz, A. Nucleation of calcium phosphate from solution. Can. J. Chem. 1967, 45, 2695-2701.

[207] Meyer, J.L., Eanes, E.D. A thermodynamic analysis of the amorphous to crystalline calcium phosphate transformation. Calcif. Tiss. Res. 1978, 25, 59-68.

[208] Meyer, J.L. Hydroxyl content of solution-precipitated calcium phosphates. Calcif. Tiss. Int. 1979, 27, 153-160.

[209] Jaeger, C., Maltsev, S., Karrasch, A. Progress of structural elucidation of amorphous calcium phosphate (ACP) and hydroxyapatite (HAp): disorder and surfaces as seen by solid state NMR. Key Eng. Mater. 2006, 309-311, 69-72.

[210] Nelson, L.S. Jr., Holt, C., Harries, J.E., Hukins, D.W.L. Amorphous calcium phosphates of different composition give very similar EXAFS spectra. Physica B 1989, 158, 105-106.

[211] Wuthier, R.E., Rice, G.S., Wallace, J.E.B. Jr., Weaver, R.L., LeGeros, R.Z., Eanes, E.D. In vitro precipitation of calcium phosphate under intracellular conditions: formation of brushite from an amorphous precursor in the absence of ATP. Calcif. Tiss. Int. 1985, 37, 401-410.

[212] Holmes, J.M., Beebe, R.A. Surface areas by gas adsorption on amorphous calcium phosphate and crystalline hydroxyapatite. Calcif. Tiss. Res. 1971, 7, 163-174.

[213] Sedlak, J.M., Beebe, R.A. Temperature programmed dehydration of amorphous calcium phosphate. J. Coll. Interf. Sci. 1974, 47, 483-489.

[214] LeGeros, R.Z., Shirra, W.P., Miravite, M.A., LeGeros, J.P. Amorphous calcium phosphates: synthetic and biological. Physico-chimie et cristallographie des apatites d'intérêt bi- ologique. Coll. Int. CNRS 1975, 230, 105-115

[215] LeGeros, R.Z. Calcium phosphates in oral biology and medicine. Monographs Oral Sci. Vol. 15. Karger, Basel, Switzerland. 1991, 201 pp.

[216] Boskey, A.L., Posner, A.S. Magnesium stabilization ob amorphous calcium phosphate: a kinetic study. Mater. Res. Bull. 1974, 9, 907-916.

[217] Blumenthal, N.C., Betts, F., Posner, A.S. Stabilization of amorphous calcium phosphate by Mg and ATP. Calcif. Tiss. Res. 1977, 23, 245-250.

[218] Abbona, F., Baronnet, A. A XRD and TEM study on the transformation of amorphous calcium phosphate in the presence of magnesium. J. Cryst. Growth 1996, 165, 98-105.

[219] Fleisch, H., Russell, R.G.G., Bisaz, S., Termine, J.D., Posner, A.S. Influence of pyrophosphate on the transformation of amorphous to crystalline calcium phosphate. Calcif. Tiss. Res. 1968, 2, 49-59.

[220] Termine, J.D., Peckauskas, R.A., Posner, A.S. Calcium phosphate formation in vitro. II. Effects of environment on amorphous-crystalline transformation. Arch. Biochem. Biophys. 1970, 140, 318-325.

[221] Bienenstock, A., Posner, A.S. Calculation of the X-ray intensities from arrays of small crystallites of hydroxyapatite. Arch. Biochem. Biophys. 1968, 124, 604-607.

[222] Tropp, J., Blumenthal, N.C., Waugh, J.S. Phosphorus NMR study of solid amorphous calcium phosphate. J. Am. Chem. Soc. 1983, 105, 22-26.

[223] Fawcett, R.W. A radial distribution function analysis of an amorphous calcium phosphate with calcium to phosphorus molar ratio of 1.42. Calcif. Tiss. Res. 1973, 13, 319-325.

[224] Betts, F., Posner, A.S. An X-ray radial distribution study of amorphous calcium phosphate. Mater. Res. Bull. 1974, 9, 353-360.

[225] Betts, F., Posner, A.S. A structural model for amorphous calcium phosphate. Trans. Am. Crystal Assoc. 1974, 10, 73-84.

[226] Eanes, E.D., Powers, L., Costa, J.L. Extended X-ray absorption fine structure (EXAFS) studies on calcium in crystalline and amorphous solids of biological interest. Cell Calcium 1981, 2, 251-262.

[227] Holt, C., Hukins, D.W.L. Structural analysis of the environment of calcium ions in crystalline and amorphous calcium phosphates by X-ray absorption spectroscopy and a hypothesis concerning the biological function of the casein micelle. Int. Dairy J. 1991, 1, 151-165.

[228] Termine, J.D., Lundy, D.R. Vibrational spectra of some phosphate salts amorphous to X-ray diffraction. Calcif. Tiss. Res. 1974, 15, 55-70.

[229] Onuma, K. Recent research on pseudobiological hydroxyapatite crystal growth and phase transition mechanism. Prog. Cryst. Growth Charact. Mater. 2006, 52, 223-245.

[230] Treboux, G., Layrolle, P., Kanzaki, N., Onuma, K., Ito, A. Symmetry of Posner's cluster. J. Am. Chem. Soc. 2000, 122, 8323-8324.

[231] Georgalis, Y., Kierzek, A.M., Saenger, W. Cluster formation 
in aqueous electrolyte solutions observed by dynamic light scattering. J. Phys. Chem. B 2000, 104, 3405-3406.

[232] Treboux, G., Layrolle, P., Kanzaki, N., Onuma, K., Ito, A. Existence of Posner's cluster in vacuum. J. Phys. Chem. A 2000, 104, 5111-5114.

[233] Kanzaki, N., Treboux, G., Onuma, K., Tsutsumi, S., Ito, A. Calcium phosphate clusters. Biomaterials 2001, 22, 2921-2929.

[234] Boldeskul, I.E., Sukhodub, L.F., Kalinkevich, A.N., Khavryutchenko, V.D. Ab initio modelling of calcium phosphate clusters and their vibrational spectra. Cond. Matter Phys. 2006, 9, 669-679.

[235] Zahn, D. Mechanisms of calcium and phosphate ion association in aqueous solution. Zeitschrift fur Anorganische und Allgemeine Chemie 2004, 630, 1507-1511.

[236] Wang, C.G., Liao, J.W., Gou, B.D., Huang, J., Tang, R.K., Tao, J.H., Zhang, T.L., Wang, K. Crystallization at multiple sites inside particles of amorphous calcium phosphate. Cryst. Growth Des. 2009, 9, 2620-2626.

[237] Kojima, Y., Sakama, K., Toyama, T., Yasue, T., Arai, Y. Dehydration of water molecules in amorphous calcium phosphate. Phosphorus Res. Bull. 1994, 4, 47-52.

[238] Wikholm, N.W., Beebe, R.A., Kittelberger, J.S. Kinetics of the conversion of monetite to calcium pyrophosphate. J. Phys. Chem. 1975, 79, 853-856.

[239] Gross, K.A., Saber-Samandari, S., Heemann, K.S. Evaluation of commercial implants with nanoindentation defines future development needs for hydroxyapatite coatings. J. Biomed. Mater. Res. B (Appl. Biomater.) 2010, 93B, 1-8.

[240] Saber-Samandari, S., Gross, K.A. The use of thermal printing to control the properties of calcium phosphate deposits. Biomaterials 2010, 31, 6386-6393.

[241] Saber-Samandari, S., Gross, K.A. Amorphous calcium phosphate offers improved crack resistance: a design feature from nature? Acta Biomater. 2011, 7, 4235-4241.

[242] Eanes, E.D., Meyer, J.L. The maturation of crystalline calcium phosphates in aqueous suspensions at physiologic $\mathrm{pH}$. Calcif. Tiss. Res. 1977, 23, 259-269.

[243] Meyer, J.L., Weatherall, C.C. Amorphous to crystalline calcium phosphate phase transformation at elevated pH. J. Coll. Interf. Sci. 1982, 89, 257-267.

[244] Ajibola, V.O., Thomas, S.A. Transformation of amorphous calcium phosphate hydroxyapatite in the presence of some ions. Bull. Chem. Soc. Ethiopia 1997, 11, 19-24.

[245] Root, M.J. Inhibition of the amorphous calcium phosphate phase transition reaction by polyphosphates and metal ions. Calcif. Tiss. Int. 1990, 47, 112-116.

[246] Wuthier, R.E., Eanes, E.D. Effect of phospholipids on the transformation of amorphous calcium phosphate to hydroxyapatite in vitro. Calcif. Tiss. Int. 1975, 19, 197-210.

[247] Termine, J.D., Eanes, E.D., Conn, K.M. Phosphoprotein modulation of apatite crystallization. Calcif. Tiss. Int. 1980, 31, 247-251.

[248] Qiu, S.M., Wen, G., Hirakawa, N., Soloway, R.D., Hong, N.K., Crowther, R.S. Glycochenodeoxycholic acid inhibits calcium phosphate precipitation in vitro by preventing the transformation of amorphous calcium phosphate to calcium hydroxyapatite. J. Clin. Investigation 1991, 88, 1265-1271.

[249] Biumenthal, N.C., Betts, F., Posner, A.S. Nucleotide stabilization of amorphous calcium phosphate. Mater. Res. Bull. $1975,10,1055-1060$.

[250] Termine, J.D., Conn, K.M. Inhibition of apatite formation by phosphorylated metabolites and macromolecules. Calcif. Tiss. Res. 1976, 22, 149-157.

[251] Tung, M.S., Brown, W.E. An intermediate state in hydrolysis of amorphous calcium phosphate. Calcif. Tiss. Int. 1983, 35, 783-790.

[252] Kazanci, M., Fratzl, P., Klaushofer, K., Paschalis, E.P. Complementary information on in vitro conversion of amorphous (precursor) calcium phosphate to hydroxyapatite from Raman microspectroscopy and wide-angle X-ray scattering. Calcif. Tiss. Int. 2006, 79, 354-359.

[253] Pekounov, Y., Petrov, O.E. Bone resembling apatite by amorphous-to-crystalline transition driven self-organisation. J. Mater. Sci. Mater. Med. 2008, 19, 753-759.

[254] Tao, J., Pan, H., Wang, J., Wu, J., Wang, B., Xu, X., Tang, R. Evolution of amorphous calcium phosphate to hydroxyapatite probed by gold nanoparticles. J. Phys. Chem. C 2008, 112, 14929-14933.

[255] Rabadjieva, D., Gergulova, R., Titorenkova, R., Tepavitcharova, S., Dyulgerova, E., Balarew, C., Petrov, O. Biomimetic transformations of amorphous calcium phosphate: kinetic and thermodynamic studies. J. Mater. Sci. Mater. Med. 2010, 21, 2501-2509.

[256] Pan, H., Liu, X.Y., Tang, R., Xu, H.Y. Mystery of the transformation from amorphous calcium phosphate to hydroxyapatite. Chem. Comm. 2010, 46, 7415-7417.

[257] Sugiura, Y., Onuma, K., Kimura, Y., Miura, H., Tsukamoto, K. Morphological evolution of precipitates during transformation of amorphous calcium phosphate into octacalcium phosphate in relation to role of intermediate phase. J. Cryst. Growth 2011, 332, 58-67.

[258] Onuma, K., Ito, A. Cluster growth model for hydroxyapatite. Chem. Mater. 1998, 10, 3346-3351.

[259] Oyane, A., Onuma, K., Kokubo, T., Ito, A. Clustering of calcium phosphate in the system $\mathrm{CaCl}_{2}-\mathrm{H}_{3} \mathrm{PO}_{4}-\mathrm{KCl}-\mathrm{H}_{2} \mathrm{O}$. J. Phys. Chem. B 1999, 103, 8230-8235.

[260] Yin, X., Stott, M.J. Biological calcium phosphates and Posner's cluster. J. Chem. Phys. 2003, 118, 3717-3723.

[261] Eanes, E.D. The interaction of supersaturated calcium phosphate solutions with apatitic substrates. Calcif. Tiss. Res. 1976, 20, 75-89.

[262] Eanes, E.D. Crystal growth of mineral phases in skeletal tissues. Progr. Cryst. Growth Character. 1980, 3, 3-15.

[263] Termine, J.D., Eanes, E.D. Calcium phosphate deposition from balanced salt solutions. Calcif. Tiss. Res. 1974, 15, 81-84.

[264] Soares, A.M.V., Arana-Chavez, V.E., Reid, A.R., Katchburian, E. Lanthanum tracer and freeze-fracture studies suggest that compartmentalization of early bone matrix may be re- 
lated to initial mineralization. J. Anat. 1992, 181, 345-356.

[265] Bonucci, E. Fine structure of early cartilage calcification. J. Ultrastruct. Res. 1967, 20, 33-50.

[266] Anderson, H.C. Vesicles associated with calcification in the matrix of epiphyscal cartilage. J. Cell Biol. 1969, 41, 59-72.

[267] Bernard, G.W., Pease, D.C. An electron microscopic study of initial intramembranous osteogenesis. Am. J. Anat. 1969, 125, 271-290.

[268] Wuthier, R.E. Electrolytes of isolated epiphyseal chondrocytes, matrix vesicles, and extracellular fluid. Calcif. Tiss. Res. 1977, 23, 125-133.

[269] Wuthier, R.E., Gore, S.T. Partition of inorganic ions und phospholipids in isolated cell, membrane and matrix vesicle fractions: evidence for $\mathrm{Ca}-\mathrm{P}_{\mathrm{i}}$-acidic phospholipid complexes. Calcif. Tiss. Res. 1977, 24, 163-171.

[270] Eanes, E.D., Hailer, AW., Costa, J.L. Calcium phosphate formation in aqueous suspensions of multilamellar liposomes. Calcif. Tiss. Int. 1984, 36, 421-430.

[271] Sauer, G.R., Zunie, W.B., Durig, J.R., Wuthier, R.E. Fourier-transform Raman-spectroscopy of synthetic and biological calcium phosphates. Calcif. Tiss. Int. 1994, 54, 414-420.

[272] Sauer, G.R., Wuthier, R.E. Fourier-transform infrared characterization of mineral phases formed during induction of mineralization by collagenase-released matrix vesicles in vitro. J. Biol. Chem. 1988, 263, 13718-13724.

[273] Dorozhkin, S.V. Bioceramics of calcium orthophosphates. Biomaterials 2010, 31, 1465-1485.

[274] Dorozhkin, S.V. Calcium orthophosphate cements for biomedical application. J. Mater. Sci. 2008, 43, 3028-3057.

[275] Dorozhkin, S.V. Calcium orthophosphate cements and concretes. Materials 2009, 2, 221-291.

[276] Maxian, S.H., Zawadsky, J.P., Dunn, M.G. In vitro evaluation of amorphous calcium phosphate and poorly crysiallized hydroxyapatite coatings on titanium implants. J. Biomed. Mater. Res. 1993, 27, 111-117.

[277] Maxian, S.H., Zawadsky, J.P., Dunn, M.G. Mechanical and histological evaluation of amorphous calcium phosphate and poorly crystallized hydroxyapatite coatings on titanium implants. J. Biomed. Mater. Res. 1993, 27, 717-728.

[278] Garcia, F., Arias, J.L., Mayor, B., Pou, J., Rehman, I., Knowles, J., Best, S.M., León, B., Pérez-Amor, M., Bonfield, W. Effect of heat treatment on pulsed laser deposited amorphous calcium phosphate coatings. J. Biomed. Mater. Res. (Appl. Biomater.) 1998, 43, 69-76.

[279] Heimann, R.B., Wirth, R. Formation and transformation of amorphous calcium phosphates on titanium alloy surfaces during atmospheric plasma spraying and their subsequent in vitro performance. Biomaterials 2006, 27, 823-831.

[280] Liu, D.M., Chou, H.M., Wu, J.D., Tung, M.S. Hydroxyl apatite coating via amorphous calcium phosphate. Mater. Chem. Phys. 1994, 37, 39-44.

[281] Nagano, M., Nakamura, T., Kokubo, T., Tanahashi, M., Ogawa, M. Differences of bone bonding ability and degradation behaviour in vivo between amorphous calcium phosphate and highly crystalline hydroxyapatite coating. Biomaterials
1996, 17, 1771-1777.

[282] Leeuwenburgh, S.C,G., Layrolle, P., Barrère, F., de Bruijn, J., Schoonman, J., van Blitterswijk, C.A., de Groot, K. Osteoclastic resorption of biomimetic calcium phosphate coatings in vitro. J. Biomed. Mater. Res. 2001, 56, 208-215.

[283] Habibovic, P., Barrère, F., van Blitterswijk, C.A., de Groot, K., Layrolle, P. Biomimetic hydroxyapatite coating on metal implants. J. Am. Ceram. Soc. 2002, 85, 517-522.

[284] Rössler, S., Sewing, A., Stolzel, M., Born, R., Scharnweber, D., Dard, M., Worch, H. Electrochemically assisted deposition of thin calcium phosphate coatings at near-physiological pH and temperature. J. Biomed. Mater. Res. A 2003, 64A, 655-663.

[285] Lee, D.D., Tofighi, A., Aiolova, M., Chakravarthy, P., Catalano, A., Majahad, A., Knaack, D. $\alpha$-BSM ${ }^{\circledR}$ : a biomimetic bone substitute and drug delivery vehicle. Clin. Orthop. Relat. Res. 1999, 367, Suppl., S396-S405.

[286] Tofighi, A., Mounic, S., Chakravarthy, P., Rey, C., Lee, D. Setting reactions involved in injectable cements based on amorphous calcium phosphate. Key Eng. Mater. 2000, 192, 769-772.

[287] Wang, X., Ye, J., Wang, Y., Wu, X., Bai, B. Control of crystallinity of hydrated products in a calcium phosphate bone cement. J. Biomed. Mater. Res. A 2007, 81A, 781-790.

[288] van den Vreken, N.M.F., Pieters, I.Y., Declercq, H.A., Cornelissen, M.J., Verbeeck R.M.H. Characterization of calcium phosphate cements modified by addition of amorphous calcium phosphate. Acta Biomater. 2010, 6, 617-625.

[289] Drouet, C., Largeot, C., Raimbeaux, G., Estournès, C., Dechambre, G., Combes, C., Rey, C. Bioceramics: spark plasma sintering (SPS) of calcium phosphates. Adv. Sci. Technol. 2006, 49, 45-50.

[290] Mazzaoui, S.A., Burrow, M.F., Tyas, M.J., Dashper, S.G., Eakins, D., Reynolds, E.C. Incorporation of casein phosphopeptide - amorphous calcium phosphate into a glass-ionomer cement. J. Dent. Res. 2003, 82, 914-918.

[291] Uysal, T., Amasyali, M., Koyuturk, A.E., Sagdic, D. Efficiency of amorphous calcium phosphate-containing orthodontic composite and resin modified glass ionomer on demineralization evaluated by a new laser fluorescence device. Eur. J. Dent. 2009, 3, 127-134.

[292] Reynolds, E.C. Anticariogenic complexes of amorphous calcium phosphate stabilized by casein phosphopeptides: a review. Spec. Care Dentist. 1998, 18, 8-16.

[293] Tung, M.S., Eichmiller, F.C. Dental applications of amorphous calcium phosphates. J. Clinical Dentistry 1999, 10, $1-6$.

[294] Dorozhkin, S.V. Calcium orthophosphate-based biocomposites and hybrid biomaterials. J. Mater. Sci. 2009, 44, 2343-2387.

[295] Uysal, T., Ustdal, A., Nur, M., Catalbas, B. Bond strength of ceramic brackets bonded to enamel with amorphous calcium phosphate-containing orthodontic composite. Eur. J. Orthodontics 2010, 32, 281-284.

[296] Wei, D., Zhou, Y. Characteristic and biocompatibility of the $\mathrm{TiO}_{2}$-based coatings containing amorphous calcium phos- 
phate before and after heat treatment. Appl. Surf. Sci. 2009, 255, 6232-6239.

[297] Dunn, W.J. Shear bond strength of an amorphous calcium-phosphate-containing orthodontic resin cement. Am. J. Orthod. Dentofac. Orthoped. 2007, 131, 243-247.

[298] Keçik, D., Çehreli, S.B., Şar, Ç., Ünver, B. Effect of acidulated phosphate fluoride and casein phosphopeptide-amorphous calcium phosphate application on shear bond strength of orthodontic brackets. Angle Orthod. 2008, 78, 129-133.

[299] Foster, J.A., Berzins, D.W., Bradley, T.G. Bond strength of an amorphous calcium phosphate-containing orthodontic adhesive. Angle Orthod. 2008, 78, 339-344.

[300] Uysal, T., Ulker, M., Akdogan, G., Ramoglu, S.I., Yilmaz, E. Bond strength of amorphous calcium phosphate-containing orthodontic composite used as a lingual retainer adhesive. Angle Orthod. 2009, 79, 117-121.

[301] Uysal, T., Amasyali, M., Koyuturk, A.E., Ozcan, S., Sagdic, D. Amorphous calcium phosphate-containing orthodontic composites. Do they prevent demineralisation around orthodontic brackets? Austral. Orthodontic J. 2010, 26, 10-15.

[302] Bröchner, A., Christensen, C., Kristensen, B., Tranæus, S., Karlsson, L., Sonnesen, L., Twetman, S. Treatment of post-orthodontic white spot lesions with casein phosphopeptide-stabilised amorphous calcium phosphate. Clin. Oral Invest. 2011, 15, 369-373.

[303] Reynolds, E.C. Calcium phosphate-based remineralization systems: scientific evidence? Australian Dent. J. 2008, 53, 268-273.

[304] Al Zraikat, H., Palamara, J.E., Messer, H.H., Burrow, M.F., Reynolds, E.C. The incorporation of casein phosphopeptide-amorphous calcium phosphate into a glass ionomer cement. Dent. Mater. 2011, 27, 235-243.

[305] Beerens, M.W., van der Veen, M.H., van Beek, H., Ten Cate, J.M. Effects of casein phosphopeptide amorphous calcium fluoride phosphate paste on white spot lesions and dental plaque after orthodontic treatment: a 3-month follow-up. Eur. J. Oral Sci. 2010, 118, 610-617.

[306] Zhao, J., Liu, Y., Sun, W.B., Zhang, H. Amorphous calcium phosphate and its application in dentistry. Chem. Cent. J. 2011, 8, 40 (7 pages).

[307] Gupta, R., Prakash, V. CPP-ACP complex as a new adjunctive agent for remineralisation: a review. Oral Health Prev. Dent. 2011, 9, 151-165.

[308] Zhang, Q., Zou, J., Yang, R., Zhou, X. Remineralization effects of casein phosphopeptide-amorphous calcium phosphate crème on artificial early enamel lesions of primary teeth. Int. J. Paediatric Dent. 2011, 21, 374-381.

[309] Moreau, J.L., Sun, L., Chow, L.C., Xu, H.H.K. Mechanical and acid neutralizing properties and bacteria inhibition of amorphous calcium phosphate dental nanocomposite. J. Biomed. Mater. Res. B (Appl. Biomater.) 2011, 98B, 80-88.

[310] Fletcher, J., Walsh, D., Fowler, C.E., Mann, S. Electrospun mats of PVP/ACP nanofibres for remineralization of enamel tooth surfaces. CrystEngComm 2011, 13, 3692-3697.

[311] Uysal, T., Baysal, A., Uysal, B., Aydinbelge, M., Al-Qunaian,
T. Do fluoride and casein phosphopeptide-amorphous calcium phosphate affect shear bond strength of orthodontic brackets bonded to a demineralized enamel surface? Angle Orthodontist 2011, 81, 490-495.

[312] Tabrizi, A., Cakirer, B. A comparative evaluation of casein phosphopeptide-amorphous calcium phosphate and fluoride on the shear bond strength of orthodontic brackets. Eur. J. Orthodontics 2011, 33, 282-287.

[313] Hamba, H., Nikaido, T., Inoue, G., Sadr, A., Tagami, J. Effects of CPP-ACP with sodium fluoride on inhibition of bovine enamel demineralization: a quantitative assessment using micro-computed tomography. J. Dent. 2011, 39, 405-413.

[314] Ma, Z., Chen, F., Zhu, Y.J., Cui, T., Liu, X.Y. Amorphous calcium phosphate/poly(D,L-lactic acid) composite nanofibers: electrospinning preparation and biomineralization. J. Coll. Interf. Sci. 2011, 15, 371-379.

[315] Kim, I., Kim, H.J., Kim, H.M. Array of amorphous calcium phosphate particles improves cellular activity on a hydrophobic surface. J. Biomed. Mater. Res. B (Appl. Biomater.) 2010, 93B, 113-121.

[316] Sun, W., Zhang, F., Guo, J., Wu, J., Wu, W. Effects of amorphous calcium phosphate on periodontal ligament cell adhesion and proliferation in vitro. J. Medical and Biological Eng. 2008, 28, 107-112.

[317] Llena, C., Forner, L., Baca, P. Anticariogenicity of casein phosphopeptide-amorphous calcium phosphate: a review of the literature. J. Contemp. Dent. Pract. 2009, 10, 1-9.

[318] Cai, F., Shen, P., Morgan, M.V., Reynolds, E.C. Remineralization of enamel subsurface lesions in situ by sugar-free lozenges containing casein phosphopeptide-amorphous calcium phosphate. Australian Dental J. 2003, 48, 240-243.

[319] Langhorst, S.E., O’Donnell, J.N.R., Skrtic, D. In vitro remineralization of enamel by polymeric amorphous calcium phosphate composite: quantitative microradiographic study. Dent. Mater. 2009, 25, 884-891.

[320] Shen, P., Cai, F., Nowicki, A., Vincent, J., Reynolds, EC. Remineralization of enamel subsurface lesions by sugar-free chewing gum containing casein phosphopeptide-amorphous calcium phosphate. J. Dent. Res. 2001, 80, 2066-2070.

[321] Iijima, Y., Cai, F., Shen, P., Walker, G., Reynolds, C., Reynolds, E.C. Acid resistance of enamel subsurface lesions remineralized by a sugar-free chewing gum containing casein phosphopeptide-amorphous calcium phosphate. Caries Res. 2004, 38, 551-556.

[322] Cai, F., Manton, D.J., Shen, P., Walker, G.D., Cross, K.J., Yuan, Y., Reynolds. C., Reynolds, E.C. Effect of addition of citric acid and casein phosphopeptide-amorphous calcium phosphate to a sugar-free chewing gum on enamel remineralization in situ. Caries Res. 2007, 41, 377-383.

[323] Kumar, V.L.N., Itthagarun, A., King, N.M. The effect of casein phosphopeptide-amorphous calcium phosphate on remineralization of artificial caries-like lesions: an in vitro study. Australian Dental J. 2008, 53, 34-40.

[324] Ranjitkar, S., Rodriguez, J.M., Kaidonis, J.A., Richards, L.C., Townsend, G.C., Bartlett, D.W. The effect of casein phosphopeptide-amorphous calcium phosphate on erosive enamel and dentine wear by toothbrush abrasion. J. Dentistry 2009, 37, 250-254. 
[325] Ranjitkar, S., Narayana, T., Kaidonis, J.A., Hughes, T.E., Richards, L.C., Townsend, G.C. The effect of casein phosphopeptide-amorphous calcium phosphate on erosive dentine wear. Australian Dental J. 2009, 54, 101-107.

[326] Wegehaupt, F.J., Attin, T. The role of fluoride and casein phosphopeptide/amorphous calcium phosphate in the prevention of erosive/abrasive wear in an in vitro model using hydrochloric acid. Caries Res. 2010, 44, 358-363.

[327] Al-Mullahi, A.M., Toumba, K.J. Effect of slow-release fluoride devices and casein phosphopeptide/amorphous calcium phosphate nanocomplexes on enamel remineralization in vitro. Caries Res. 2010, 44, 364-371.

[328] Giniger, M., MacDonald, J., Spaid, M., Felix, H. A 180-day clinical investigation of the tooth whitening efficacy of a bleaching gel with added amorphous calcium phosphate. J. Clinical Dentistry 2005, 16, 11-16.

[329] Giniger, M., MacDonald, J., Ziemba, S., Felix, H. The clinical performance of professionally dispensed bleaching gel with added amorphous calcium phosphate. J. Am. Dental Association 2005, 136, 383-392.

[330] Ramalingam, L., Messer, L.B., Reynolds, E.C. Adding casein phosphopeptide-amorphous calcium phosphate to sports drinks to eliminate in vitro erosion. Pediatric Dentistry 2005, 27, 61-67.

[331] Panich, M., Poolthong, S. The effect of casein phosphopeptide-amorphous calcium phosphate and a cola soft drink on in vitro enamel hardness. J. Am. Dental Assoc. 2009, 140, 455-460.

[332] Silva, K.G., Pedrini, D., Delbem, A.C.B., Ferreira, L., Cannon, M. In situ evaluation of the remineralizing capacity of pit and fissure sealants containing amorphous calcium phosphate and/or fluoride. Acta Odontologica Scandinavica 2010, 68, 11-18.

[333] Bayrak, S., Tunc, E.S., Sonmez, I.S., Egilmez, T., Ozmen, B. Effects of casein phosphopeptide-amorphous calcium phosphate (CPP-ACP) application on enamel microhardness after bleaching. Am. J. Dentistry 2009, 22, 393-396.

[334] Yengopal, V., Mickenautsch, S. Caries preventive effect of casein phosphopeptide-amorphous calcium phosphate (CPP-ACP): a meta-analysis. Acta Odontologica Scandinavica 2009, 67, 321-332.

[335] Walker, G.D., Cai, F., Shen, P., Reynolds, C., Ward, B., Fone, C., Honda, S., Koganei, M., Oda, M., Reynolds, E.C. Increased remineralization of tooth enamel by milk containing added casein phosphopeptide-amorphous calcium phosphate. J. Dairy Res. 2006, 73, 74-78.

[336] Walker, G.D., Cai, F., Shen, P., Bailey, D.L., Yuan, Y., Cochrane, N.J., Reynolds, C., Reynolds, E.C. Consumption of milk with added casein phosphopeptide-amorphous calcium phosphate remineralizes enamel subsurface lesions in situ. Australian Dental J. 2009, 54, 245-249.

[337] Willershausen, B., Schulz-Dobrick, B., Gleissner, C. In vitro evaluation of enamel remineralisation by a casein phospho- peptide-amorphous calcium phosphate paste. Oral Health \& Preventive Dentistry 2009, 7, 13-21.

[338] Mei, H.L., Chen, L.Y., Zhang, D., Zhang, P.L., Liu, B., Zhao, W., Qi, H.Y. Effects of casein phosphopeptide-stabilized amorphous calcium phosphate solution on enamel remineralization. J. Clin. Rehabil. Tiss. Eng. Res. 2009, 13, 4825-4828.

[339] Shinohara, M., Uchida, K., Shimada, S., Tomioka, K., Suzuki, N., Minegishi, T., Kawahashi, S., Yoshikawa, Y., Ohashi, N. Novel concentration method for the detection of norovirus and sapovirus from water using minute particles of amorphous calcium phosphate. J. Medical Microbiology 2011, 60, 780-786.

[340] Dorozhkin, S.V. Nanodimensional and nanocrystalline apatites and other calcium orthophosphates in biomedical engineering, biology and medicine. Materials 2009, 2, 1975-2045.

[341] Dorozhkin, S.V. Nanosized and nanocrystalline calcium orthophosphates. Acta Biomater. 2010, 6, 715-734.

[342] Suvorova, E.I., Buffat, P.A. Size effect in X-ray and electron diffraction patterns from hydroxyapatite particles. Crystallogr. Rep. 2001, 46, 722-729.

[343] Suvorova, E.I., Buffat, P.A. Electron diffraction and high resolution transmission electron microscopy in the characterization of calcium phosphate precipitation from aqueous solutions under biomineralization conditions. Eur. Cell Mater. 2001, 1, 27-42.

[344] Celotti, G., Tampieri, A., Sprio, S., Landi, E., Bertinetti, L., Martra, G., Ducati. C. Crystallinity in apatites: how can a truly disordered fraction be distinguished from nanosize crystalline domains? J. Mater. Sci. Mater. Med. 2006, 17, 1079-1087.

[345] Tadic, D., Beckmann, F., Schwarz, K., Epple, M. A novel method to produce hydroxyapatite objects with interconnecting porosity that avoids sintering. Biomaterials 2004, 25, 3335-3340.

[346] Chandanshive, B., Dyondi, D., Ajgaonkar, V.R., Banerjee, R., Khushalani, D. Biocompatible calcium phosphate based tubes. J. Mater. Chem. 2010, 20, 6923-6928.

[347] Scott, P.R., Crow, J.A., LeGeros, R.Z., Kruger, M.B. A pressure-induced amorphous phase transition in magnesium-substituted $\beta$-tricalcium phosphate. Solid State Comm. 2011, 151, 1609-1611.

[348] Xu, H.H.K., Moreau, J.L., Sun, L., Chow, L.C. Nanocomposite containing amorphous calcium phosphate nanoparticles for caries inhibition. Dent Mater. 2011, 27, 762-769.

[349] Gross, K.A., Young, C.J., Beck, M.A., Keebaugh, E.W., Bronts, T.J., Saber-Samandari, S., Riley, D.P. Characterization and dissolution of functionalized amorphous calcium phosphate biolayers using single-splat technology. Acta Biomater. 2011, 7, 2270-2275.

[350] Dosen, A., Giese, R.F. Thermal decomposition of brushite, $\mathrm{CaHPO}_{4} \cdot 2 \mathrm{H}_{2} \mathrm{O}$ to monetite $\mathrm{CaHPO}_{4}$ and the formation of an amorphous phase. Am. Mineralogist 2011, 96, 368-373. 